\title{
RpoN $\left(\sigma^{54}\right)$ Controls Production of Antifungal Compounds and Biocontrol Activity in Pseudomonas fluorescens CHAO
}

\author{
Maria Péchy-Tarr, ${ }^{1}$ Mélanie Bottiglieri, ${ }^{1}$ Sophie Mathys, ${ }^{1}$ Kirsten Bang Lejbølle, ${ }^{1}$ Ursula Schnider-Keel, ${ }^{1}$ \\ Monika Maurhofer, ${ }^{2}$ and Christoph Keel ${ }^{1}$
}

${ }^{1}$ Département de Microbiologie Fondamentale, Université de Lausanne, $\mathrm{CH}-1015$ Lausanne, Switzerland; ${ }^{2}$ Institut für Pflanzenwissenschaften/Phytopathologie, Eidgenössische Technische Hochschule (ETH), CH-8092 Zürich, Switzerland

Submitted 14 July 2004. Accepted 8 November 2004.

\begin{abstract}
Pseudomonas fluorescens CHA0 is an effective biocontrol agent of root diseases caused by fungal pathogens. The strain produces the antibiotics 2,4-diacetylphloroglucinol (DAPG) and pyoluteorin (PLT) that make essential contributions to pathogen suppression. This study focused on the role of the sigma factor $\operatorname{RpoN}\left(\sigma^{54}\right)$ in regulation of antibiotic production and biocontrol activity in $P$. fluorescens. An rpoN in-frame-deletion mutant of CHAO had a delayed growth, was impaired in the utilization of several carbon and nitrogen sources, and was more sensitive to salt stress. The $r p o N$ mutant was defective for flagella and displayed drastically reduced swimming and swarming motilities. Interestingly, the $r p o N$ mutant showed a severalfold enhanced production of DAPG and expression of the biosynthetic gene phlA compared with the wild type and the mutant complemented with monocopy $r p o N^{+}$. By contrast, loss of RpoN function resulted in markedly lowered PLT production and plt gene expression, suggesting that RpoN controls the balance of the two antibiotics in strain CHAO. In natural soil microcosms, the $r p o N$ mutant was less effective in protecting cucumber from a root rot caused by Pythium ultimum. Remarkably, the mutant was not significantly impaired in its root colonization capacity, even at early stages of root infection by Pythium spp. Taken together, our results establish RpoN for the first time as a major regulator of biocontrol activity in Pseudomonas fluorescens.
\end{abstract}

Additional keyword: rhizosphere.

Certain strains of fluorescent Pseudomonas spp. that are closely associated with roots can protect crop plants from soilborne diseases caused by pathogenic fungi, oomycetes, and bacteria (Cook et al. 1995; Keel and Défago 1997). In addition to their capacity to efficiently colonize plant roots,

Corresponding author: C. Keel; Telephone: +41 2169256 36; Fax: +41 2169256 05; E-mail: christoph.keel@unil.ch

Current address of Kirsten Bang Lejbølle: Department of Environmental Chemistry and Microbiology, The National Environmental Research Institute, DK-4000 Roskilde, Denmark.

Current address of Sophie Mathys: Institut für Lebensmittel- und Ernährungswissenschaften, Eidgenössische Technische Hochschule, $\mathrm{CH}-$ 8803 Rüschlikon, Switzerland.

Nucleotide and amino acid sequence data reported are available in the GenBank and EMBL databases under accession numbers AY341911 and AY459536. the production of metabolites that are inhibitory to plantpathogenic rhizosphere inhabitants is considered to be one of the principal backbones of biocontrol activity in many of these bacteria (Haas and Keel 2003; Raaijmakers et al. 2002; Thomashow and Weller 1995). 2,4-Diacetylphloroglucinol (DAPG) and pyoluteorin (PLT) are two metabolites that have received particular attention because of their broad-spectrum antifungal and antibacterial activity (Haas and Keel 2003; Keel et al. 1992; Maurhofer et al. 1992, 1995; Raaijmakers et al. 2002; Thomashow and Weller 1995). Some effective biocontrol pseudomonads produce both DAPG and PLT (Keel et al. 1996), among them the well-characterized Pseudomonas fluorescens strain CHA0 (Haas and Keel 2003; Keel and Défago 1997; Voisard et al. 1994) and the very closely related $P$. fluorescens strain Pf-5 (Howell and Stipanovic 1980; Kraus and Loper 1995; Sarniguet et al. 1995). DAPG and PLT make major contributions to biocontrol activity in these strains. DAPG has been shown to contribute to the protection of wheat from take-all disease (Keel et al. 1992) and of tobacco from black root rot (Keel et al. 1990), whereas PLT has been associated mainly with the suppression of root rot and damping-off diseases caused by Pythium spp. (Howell and Stipanovic 1980; Kraus and Loper 1995; Maurhofer et al. 1994).

The DAPG and PLT biosynthetic genes are organized as clusters, probably operons, and have been identified in several Pseudomonas strains (Haas et al. 2000; Haas and Keel 2003). The DAPG locus comprises the phlACBD biosynthetic genes and the divergently transcribed phlF gene located upstream of phlA and encoding a pathway-specific transcriptional repressor (Bangera and Thomashow 1999; Delany et al. 2000; SchniderKeel et al. 2000). The PLT biosynthetic genes pltLABCDEFG are preceded by the divergently transcribed pltR gene, which encodes a pathway-specific transcriptional activator (Haas and Keel 2003; Nowak-Thompson et al. 1999). Remarkably, the biosyntheses of both compounds, DAPG and PLT, are controlled by positive autoregulatory circuits (Brodhagen et al. 2004; Haas and Keel 2003; Schnider-Keel et al. 2000). There is evidence for a molecular cross-talk between the DAGP and PLT biosynthetic pathways, inasmuch as the two metabolites were found to display an inverse relationship in which each metabolite, besides activating its own biosynthesis, represses the synthesis of the other metabolite (Brodhagen et al. 2004; Haas and Keel 2003; Schnider-Keel et al. 2000). In addition, levels of DAPG and PLT production may be modulated by other phenolic metabolites released by microorganisms and plant roots in the rhizosphere as well as in response to certain min- 
eral and carbon sources (Duffy and Défago 1999; Haas and Keel 2003; Maurhofer et al. 2004; Notz et al. 2001; SchniderKeel et al. 2000).

In addition to the pathway-specific regulatory mechanisms, a series of global regulatory networks that respond to environmental and cell density-dependent signals and probably also to the physiological status of the bacterium contribute to the control of DAPG and PLT biosyntheses (Haas et al. 2000; Haas and Keel 2003; Thomashow and Weller 1995). They include a regulatory cascade controlled by a two-component system composed of the sensor kinase GacS and the response regulator GacA that positively controls antibiotic biosynthesis upon activation by a yet unidentified quorum sensing-signal (Haas and Keel 2003; Valverde et al. 2003; Zuber et al. 2003). An additional level of control may be provided by the relative concentrations of the housekeeping $\sigma$ factor RpoD and the stress and stationary phase $\sigma$ factor RpoS in the bacterial cell. In $P$. fluorescens CHA0, overexpression of the housekeeping $\sigma$ factor RpoD enhances DAPG and PLT production in vitro and in the rhizosphere, resulting in improved biocontrol or phytotoxic effects depending on the plant species (Maurhofer et al. 1992, 1995; Schnider et al. 1995). Likewise, an $\operatorname{rpoS}$ mutant of the related strain Pf-5 shows strongly enhanced PLT and DAPG production (Sarniguet et al. 1995), whereas rpoS overexpression in strain CHA0 was found to shut off PLT production (Haas and Keel 2003).

In recent years, the alternative $\sigma$ factor $\operatorname{RpoN}\left(\sigma^{54}\right)$ has evolved as an important regulator of virulence in pathogenic pseudomonads. RpoN works in concert with specialized transcriptional activators (enhancer-binding proteins) to control the expression of genes coding for very diverse functions in response to environmental stimuli (Buck et al. 2000; Merrick 1993). Typical features that depend on RpoN function in pseudomonads and in a broad range of other bacteria include motility and diverse metabolic functions such as transport and metabolism of various nitrogen and carbon sources (Cases et al. 2003; Köhler et al. 1989; Reitzer and Schneider 2001; Studholme and Buck 2000). In the plant-pathogenic P. syringae pvs. maculicola and glycinea, RpoN is required for the expression of the pathogenicity-related hrp genes, for the production of the phytotoxin coronatine, and for full virulence on host plants (Alarcón-Chaidez et al. 2003; Hendrickson et al. 2000a,b). Similarly, in the opportunistic human pathogen $P$. aeruginosa, RpoN regulates the expression of a series of virulence factors, including flagella, pili, alginate, rhamnolipid biosurfactants, exotoxins, cyanide, and pyocyanin, and contributes to virulence in certain animal models (Boucher et al. 2000; Hendrickson et al. 2001; Heurlier et al. 2003; Ishimoto and Lory 1989; Studholme and Buck 2000; Thompson et al. 2003; Totten et al. 1990). Recent evidence suggests that the RpoN regulon in pathogenic pseudomonads may be interlinked with other regulatory networks, in particular those controlled by the GacS/GacA two-component system, by quorum-sensing systems, and by other $\sigma$ factors, but the exact mechanisms involved are not yet fully understood (Boucher et al. 2000; Chatterjee et al. 2003; Hendrickson et al. 2000a; Heurlier et al. 2003; Thompson et al. 2003).

To our best knowledge, a regulatory role for RpoN in plantbeneficial pseudomonads has not been described so far. To address this issue, we have cloned and sequenced the rpoN locus from $P$. fluorescens CHA0. In the present study, we show that an $\operatorname{rpoN}$ in-frame-deletion mutant of strain $\mathrm{CHA} 0$ displays several phenotypes that typically are associated with loss of RpoN function, including a drastically reduced motility and a defect in the utilization of several nitrogen and carbon sources. We report that rpoN mutation in strain CHA0 entails increased sensitivity to salt stress but does not affect tolerance to oxidative stress. Finally, we demonstrate that deletion of $r p o N$ in $\mathrm{CHA} 0$ results in an altered expression of the antifungal compounds DAPG and PLT and in a strongly reduced capacity to control Pythium root rot of cucumber, thus providing the first evidence that RpoN is a further key regulator of biocontrol activity in plant-beneficial pseudomonads.

\section{RESULTS}

\section{Characterization of the chromosome region containing rpoN in $P$. fluorescens CHAO.}

We cloned and sequenced a $2.2-\mathrm{kb}$ chromosomal region in P. fluorescens strain CHA0 containing rpoN and adjacent genes (Fig. 1) in an arrangement identical to that described for other Pseudomonas spp. (Alarcón-Chaidez and Bender 2001; Härtig and Zumft 1998; Jin et al. 1994; Köhler et al. 1994; Stover et al. 2000). The deduced product (497 amino acids) of the rpoN gene of $P$. fluorescens $\mathrm{CHA} 0$ is very similar to $\sigma$ factor RpoN $\left(\sigma^{54}\right)$ of $P$. syringae pv. maculicola (accession no. AF199600; 95\% identity), P. syringae pv. glycinea (AF283815; 93\% identity), P. syringae pv. tomato (AE016872; 96\% identity), $P$. syringae pv. syringae (ZP_00126321; 95\% identity), $P$. putida (M24916 and X16474; 91\% identity); $P$. aeruginosa (AE004860 and L26916; 86\% identity), $P$. stutzeri MK21 (AJ223088; 85\%), and Azotobacter vinelandii (X05888; 80\% identity). The predicted protein sequence of RpoN of strain CHA0 is in accordance with the highly conserved domain structure identified in RpoN of other bacteria, in particular with respect to the helix-turn-helix motif (MKPLVLHDIAEAVGMHESTISRVTTQ) and the RpoNbox motif (ARRTVAKYRE) in the C-terminus which are identical to those in other pseudomonads and in Azotobacter sp. (Alarcón-Chaidez and Bender 2001; Buck et al. 2000; Jin et al. 1994; Merrick 1993). RpoN recognizes an YTGGCAC R-N4-TTGCW consensus sequence situated at positions -24 and -12 relative to the transcription start site (Barrios et al. 1999; Reitzer and Schneider 2001; Studholme and Buck 2000). A putative RpoN recognition site (CAGGCATATAAT TTGCT) was found 89 bp upstream of the translational start site of rpoN of strain CHA0. Remarkably, the sequence and location of the RpoN recognition site appears to be highly conserved in $P$. fluorescens, $P$. syringae (Alarcón-Chaidez and Bender 2001), P. putida (Köhler et al. 1994), and P. aeruginosa (Jin et al. 1994).

As in other pseudomonads, rpoN in P. fluorescens CHA0 is flanked by an upstream open reading frame (ORF) coding for the ATPase component of an ABC-type transport system (ORFA; Fig. 1) and by two downstream ORFs (ORFB and ORFC) encoding, respectively, a protein with putative $\sigma^{54}$ modulating function and the enzyme IIA (PtsN) of the phosphoenolpyruvate/sugar phosphotransferase system (AlarcónChaidez and Bender 2001; Cases et al. 1999; Härtig and Zumft 1998; Jin et al. 1994; Köhler et al. 1994; Stover et al. 2000). The amino acid sequences of the deduced products of ORFB and the partially sequenced ORFA and ORFC were found to be between 72 and $89 \%$ identical to the corresponding sequences of their counterparts in $P$. syringae, $P$. aeruginosa, $P$. putida, $P$. stutzeri, and A. vinelandii. Homologues of these ORFs also have been found in an identical arrangement in the rpoN regions of various other gram-negative bacterial species, but their precise function and their relation to RpoN function is not yet fully understood (Merrick 1993; Michiels et al. 1998). It has been suggested that the products of the downstream rpoN-linked genes might contribute to the modulation of RpoN activity or might be involved in the coregulation of some of the RpoN promoters (Cases et al. 1999; Jin et al. 1994; Merrick 1993; Michiels et al. 1998). 
Growth characteristics of an rpoN mutant of $P$. fluorescens.

A chromosomal rpoN in-frame mutation was created in $P$. fluorescens $\mathrm{CHA} 0$ (Fig. 1) as described below. The rpoN mutant (CHA250) was complemented by a single copy of intact $r p o N^{+}$introduced into the chromosomal Tn7 attachment site, resulting in strain CHA251. The constructs then were compared with the wild type for changes in growth characteristics. In nutrient-rich media, the rpoN mutant $\mathrm{CHA} 250$ had a markedly longer doubling time (approximately $75 \mathrm{~min}$ in King's medium B [KMB] broth, $71 \mathrm{~min}$ in Luria-Bertani [LB] broth, and 133 min in glycerol-Casamino acids medium [GCM]) than the wildtype CHA0 and the complemented mutant CHA251 (approximately $44 \mathrm{~min}$ in KMB broth, $38 \mathrm{~min}$ in LB broth, and $72 \mathrm{~min}$ in GCM). However, in the stationary growth phase, all three strains had reached similar final cell densities in these media (data not shown). In the following, KMB broth was chosen as the standard culture medium for most of the experiments because growth kinetics of the rpoN mutant most resembled those of the wild type in this medium, except that the mutant had an extended lag phase and a slightly slower growth during the exponential phase.

Unlike wild-type CHA0 (doubling time of $99 \mathrm{~min}$ ), the rpoN mutant CHA250 was unable to grow in the minimal glucoseammonium medium (OSG). Therefore, the capacity of the mutant to utilize different nitrogen sources was tested in M9 minimal salt medium in which $\mathrm{NH}_{4} \mathrm{Cl}$ was replaced or supplemented by an alternative nitrogen source. In contrast to the wild type or the complemented mutant, the rpoN mutant was unable to grow in M9 minimal medium when it contained $\mathrm{NH}_{4} \mathrm{Cl}$, histidine, or proline as the sole nitrogen source. The growth of the mutant in M9 minimal medium supplemented or not with $\mathrm{NH}_{4} \mathrm{Cl}$ could be restored largely by addition of glutamine, glutamate, or aspartate to the medium (data not shown). In addition, carbon source utilization profiles were determined for wild-type CHAO and the rpoN mutant using Biolog GN2 and GP2 plates. Of the 128 carbon sources tested, 53 were assimilated by strain $\mathrm{CHAO}$ and, of these, the rpoN mutant could not utilize 18 (i.e., $N$-acetyl-Dglucosamine, cis-aconitate, 2-aminoethanol, D-arabitol, DL- carnitine, citrate, L-histidine, $\gamma$-hydroxybutyrate, $\alpha$-ketoglutarate, D-mannitol, monomethylsuccinate, L-proline, L-serine, succinamate, succinate, L-threonine, D-trehalose, and urocanate). Moreover, CHA250 displayed poor growth on 15 additional carbon sources (data not shown).

Overexpression of rpoN from the multicopy plasmids pME8013 $\left(P_{\text {rpoN }}-r p o N^{+}\right)$and pME8014 $\left(P_{\text {lac }}-r p o N^{+}\right)($Fig. 1) in a CHA0 background did not significantly affect growth characteristics of the derivatives in rich and minimal media compared with the wild-type strain (data not shown). In conclusion, loss of RpoN function in P. fluorescens, as in other Pseudomonas spp. (Alarcón-Chaidez et al. 2003; Köhler et al. 1989; Totten et al. 1990), results in some growth defects, particularly with respect to the utilization of certain $\mathrm{C}$ and $\mathrm{N}$ sources.

\section{RpoN is required for motility in $\boldsymbol{P}$. fluorescens.}

For $P$. aeruginosa, three types of surface motility have been described: i) swimming motility, which depends on the polar flagellum and can be observed on low-agar medium; ii) swarming motility, which occurs as a coordinate cell movement on semisolid agar surfaces and requires flagella, biosurfactants, and, in some cases, also type IV pili; and iii) twitching motility, which is mediated by type IV pili and takes place at surface interfaces (Köhler et al. 2000; Rashid and Kornberg 2000). Here, we report that these modes of surface translocation also can be observed in $P$. fluorescens (Table 1; Fig. 2). As in $P$. aeruginosa, swarming motility in $P$. fluorescens strain CHA0 was accompanied by a typical dendritic pattern of the swarm colony (Fig. 2A). Loss of RpoN function had a dramatic impact on the surface motility of $P$. fluorescens. Swimming and swarming motilities in the rpoN mutant CHA250 were drastically reduced, whereas twitching motility appeared to be less affected (Table 1; Fig. 2A and B). Motility could be restored to wild-type levels by complementation of the mutant with a single copy of intact $r p o N^{+}$(Table 1). Overexpression of rpoN from its natural promoter in $\mathrm{CHA0/pME8013}$ and from the constitutive lac promoter in CHA0/pME8014 had no statistically significant effect on motility (Table 1). Transmission electron microscopy confirmed that cells of the rpoN mutant

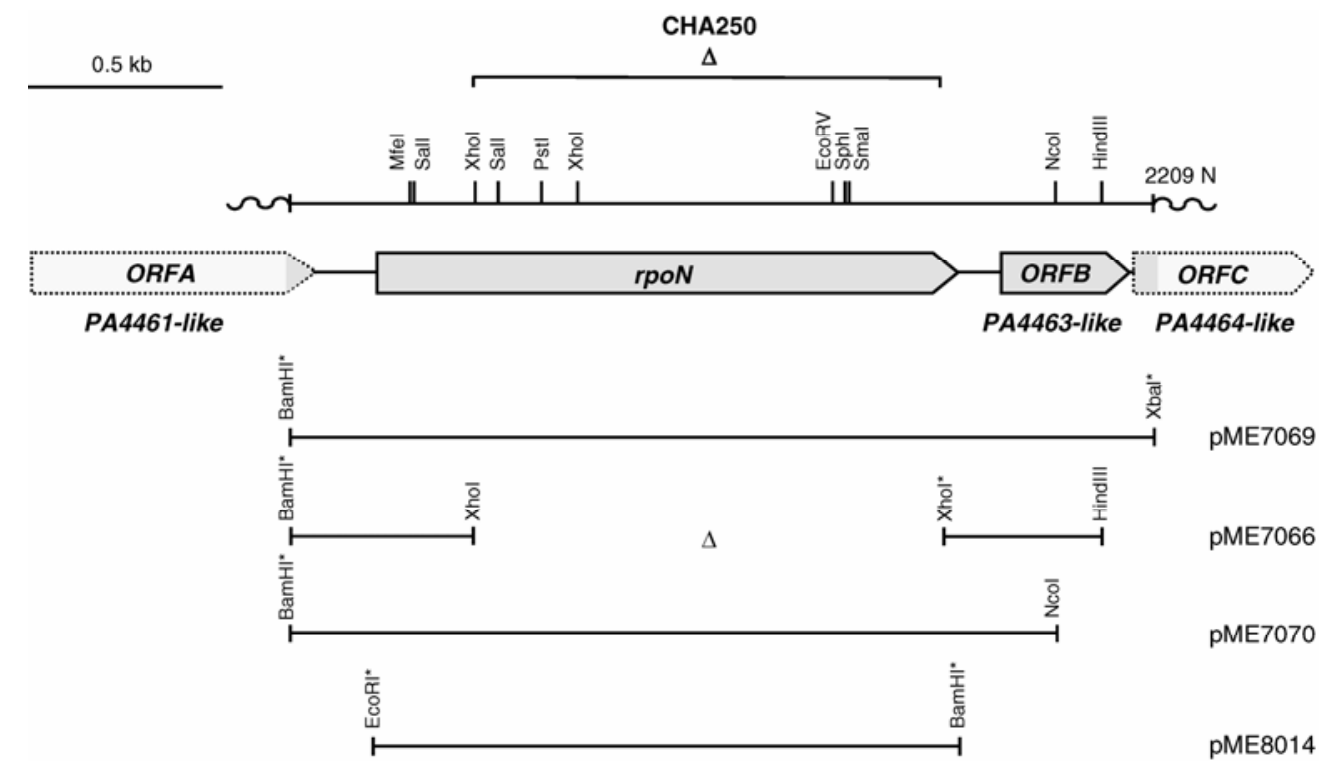

Fig. 1. Organization of the rpoN region in Pseudomonas fluorescens strain CHA0; $\Delta=$ region deleted in strain CHA250 and in plasmid pME7066. The shaded arrows show the genes sequenced or partly sequenced on the 2209-bp BamHI-XbaI fragment of pME7069. Open reading frame (ORF)A, ORFB, and ORFC designate ORFs that are highly similar to PA4461, PA4463, and PA4464 (ptsN), respectively, of P. aeruginosa PAO1 (Stover et al. 2000). The bars indicate the fragments cloned into the vectors pME6000, pME3087, pME6182, and pME6551 to give pME7069, pME7066, pME7070, and pME8014, respectively. The fragment inserted in pME7070 was used to complement the rpoN mutation in CHA250 with single-copy rpoN ${ }^{+}$using the mini-Tn7 delivery system. Artificial restriction sites are marked with an asterisk. 
were defective for flagella, whereas swarmer cells of the wild type, the complemented mutant, and the rpoN-overexpressing mutants possessed two to three, sometimes even more, polar flagella (Fig. 2C; data not shown). However, at least under the experimental conditions chosen here, we did not detect pili on swarmer cells. On swim plates, $P$. fluorescens cells with intact rpoN generally had one polar flagellum, although occasionally cells with two flagella also could be observed (data not shown). In summary, our results establish that RpoN, as in other bacterial species, is essential for flagella formation and thus for motility in P. fluorescens.

\section{Contribution of RpoN to stress tolerance in $\boldsymbol{P}$. fluorescens.}

We next tested whether lack of RpoN affects growth of $P$. fluorescens in response to osmotic stress. For this purpose, we determined the doubling times of strain $\mathrm{CHA} 0$ and its derivatives during exponential growth of the bacteria in KMB broth supplemented with $\mathrm{NaCl}$ or sorbitol. The rpoN mutant was significantly more sensitive to high salinity than the wild type. The doubling time of CHA250 cells quadrupled when they were exposed to $0.6 \mathrm{M} \mathrm{NaCl}$, whereas it was only threefold longer in $\mathrm{CHA} 0$ and the complemented rpoN mutant $\mathrm{CHA} 251$ (Table 2). This effect also could be observed at higher salt concentrations $(0.8 \mathrm{M} \mathrm{NaCl})$ (data not shown). No such difference in stress sensitivity between the wild type and the rpoN mutant could be noted when bacteria were exposed to $1.2 \mathrm{M}$ sorbitol (Table 2). The mutant complemented with monocopy $r p o N^{+}$ and CHA0 derivatives overxpressing rpoN from plasmids pME8013 or pME8014 exhibited stress tolerances largely similar to that of the wild type (Table 2).

To test the contribution of RpoN to bacterial survival in response to osmotic stress, stationary-phase cells were exposed to $1.2 \mathrm{M} \mathrm{NaCl}$ or $2.4 \mathrm{M}$ sorbitol (i.e., conditions which no longer allowed $P$. fluorescens to grow). In contrast to the wildtype CHA0 and the rpoN-overexpressing derivative CHA0/pME8014, culturability in the rpoN mutant CHA250 significantly dropped soon after exposure to salt stress (Fig. 3). By contrast, no such differences could be observed when bacteria were exposed to $2.4 \mathrm{M}$ sorbitol (data not shown).

To determine whether inactivation of $r p o N$ affects the susceptibility of $P$. fluorescens to agents generating reactive oxygen intermediates (ROIs), wild-type strain $\mathrm{CHA} 0$, the rpoN deletion mutant, and the $r p o N$-overexpressing derivatives were exposed to paraquat, hydrogen peroxide, and sodium hypochlorite. All mutant strains were found to display wild-type susceptibility to various concentrations of these agents (data not shown). In contrast, an rpoS mutant of strain CHA0 (Heeb et al. 2002) (Table 3) included as a control was significantly more sensitive to oxidative stress than the parental strain (data not shown), thus confirming previous findings of Sarniguet and associates (1995) obtained with an rpoS mutant of $P$. fluorescens $\mathrm{Pf}-5$. In summary, these results suggest that RpoN contributes to tolerance of $P$. fluorescens to conditions of high salinity, but is not required for tolerance toward ROIs and osmotic stress induced by sorbitol.

\section{RpoN controls the production} of antifungal compounds in $\boldsymbol{P}$. fluorescens.

We then evaluated the effect of the rpoN mutation on the production of the antifungal compounds DAPG and PLT, which make significant contributions to the biocontrol activity of $P$. fluorescens CHA0. For this purpose, we followed the expression of lacZ reporter fusions to the DAPG and PLT biosynthetic genes in bacterial cultures growing in KMB broth and we determined the production of the two antifungal compounds in parallel. Interestingly, the expression of a phlA-lacZ transcriptional fusion carried by pME6710 (Schnider-Keel et al. 2000) was enhanced severalfold in the $\operatorname{rpoN}$ mutant as of the end of the exponential growth phase compared with the wild-type CHA0 and the complemented mutant CHA251 (Fig.
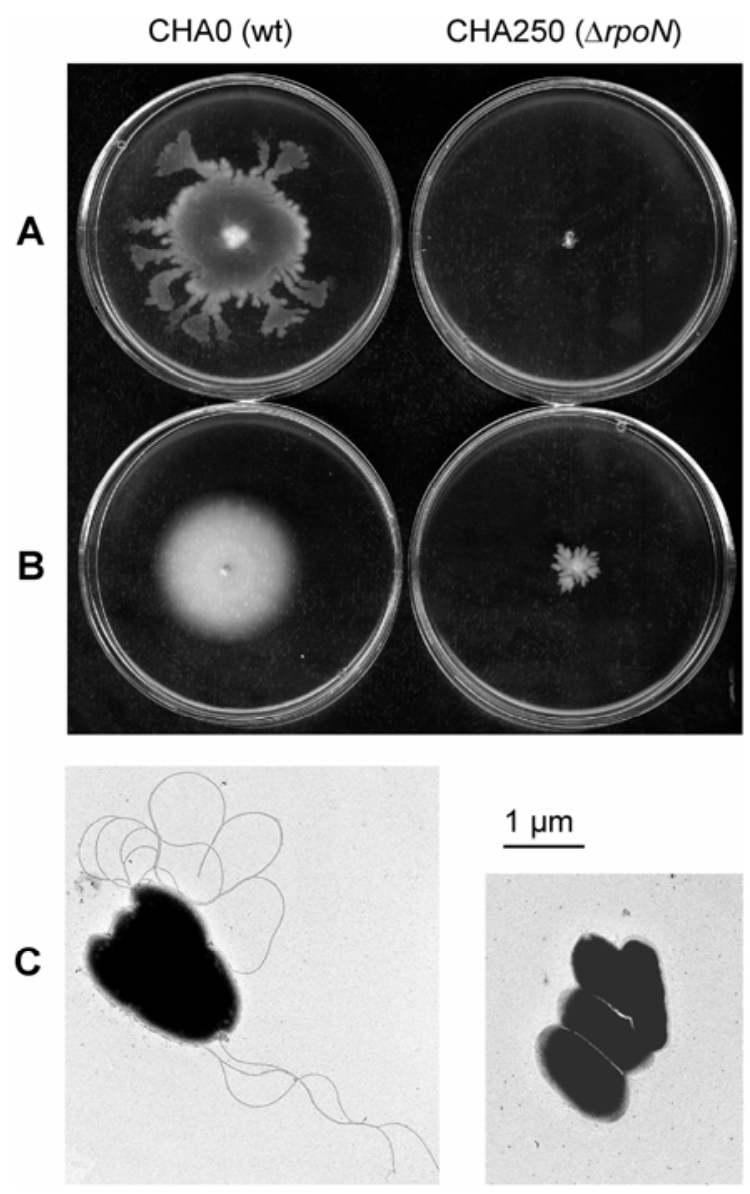

Fig. 2. Swarming and swimming motilities of Pseudomonas fluorescens wild-type CHA0 (left) and its rpoN mutant CHA250 (right) on $\mathbf{A}$, swarm plates (nutrient broth with $0.5 \%$ glucose and $0.5 \%$ agar) and $\mathbf{B}$, swim plates (tryptone broth with $0.3 \%$ agar), respectively, after a 48-h incubation at room temperature. C, Electron micrographs showing flagellated cells of strain CHA0 (left) and nonflagellated cells of the rpoN mutant CHA250 (right) taken from the edge of swarm colonies.

Table 1. Contribution of RpoN to swimming, swarming, and twitching motilities of Pseudomonas fluorescens $\mathrm{CHA} 0^{\mathrm{z}}$

\begin{tabular}{|c|c|c|c|c|}
\hline Strain & Relevant genotype & Swim area, $\%$ wt & Swarm area, \% wt & Twitch area, $\%$ wt \\
\hline $\mathrm{CHA0}$ & Wild type & $100 \pm 12$ & $100 \pm 8$ & $100 \pm 6$ \\
\hline CHA250 & $\Delta r p o N$ & $32 \pm 4$ & $4 \pm 1$ & $60 \pm 12$ \\
\hline CHA251 & $\Delta r p o N$ attTn7::rpoN ${ }^{+}$ & $110 \pm 4$ & $118 \pm 27$ & $100 \pm 20$ \\
\hline CHA0/pME8013 & $P_{\mathrm{rpoN}}-\mathrm{rpoN}^{+}$ & $122 \pm 17$ & $105 \pm 12$ & $88 \pm 19$ \\
\hline CHA0/pME8014 & $P_{\text {lac }}-r p o N^{+}$ & $110 \pm 8$ & $79 \pm 24$ & $128 \pm 21$ \\
\hline
\end{tabular}

\footnotetext{
${ }^{\mathrm{z}}$ Diameter of bacterial displacement on swim plates, swarm plates, and twitch plates after incubation for $24 \mathrm{~h}$ (swim and swarm plates) and 4 to 5 days (twitch plates) at room temperature, assessed as described in the Materials and Methods section. Data are expressed as percentage of the diameters obtained for the wild type which were arbitrarily set to $100 \%$. Data represent the means \pm standard deviation from three experiments with 12 replicate plates per treatment in each experiment.
} 
4A). In contrast, expression levels of a pltA-lacZ transcriptional fusion carried by pME8007 (Table 3) were two- to threefold lower in the rpoN mutant than in the $r p o N^{+}$strains CHA0 and CHA251 (Fig. 4B). RpoN overexpression in strain CHA0 carrying the multicopy plasmids pME8013 or pME8014 (Table 3) did not significantly alter phl or plt gene expression (data not shown). The kinetics of DAPG and PLT production paralleled the expression of the phlA-lacZ and pltAlacZ reporter constructs: DAPG levels were enhanced whereas PLT levels were reduced in cultures of the rpoN mutant (Fig. 4C and D). The rpoN-overexpressing strains CHA0/pME8013 and CHA0/pME8014 produced wild-type levels of DAPG and PLT (data not shown). The strong decrease of DAPG and PLT levels at the end of the experiments may be due to degradation of the two compounds by the producer strains (Schnider-Keel et al. 2000; our unpublished observations). Experiments also were carried out using a phlA'-lacZ translational fusion on pME6259 (Schnider-Keel et al. 2000) and a pltA' - lacZ translational fusion on pME6751 (Table 3), and kinetics of gene expression in the rpoN mutant, the wild type, and the complemented rpoN mutant were found to be almost identical to those obtained with the transcriptional reporter fusions described above (data not shown). Glycerol is known to favor PLT production in P. fluorescens (Duffy and Défago 1999; SchniderKeel et al. 2000); therefore, the influence of RpoN on phlA expression also was tested in $\mathrm{KMB}$ broth in which glycerol was replaced by glucose $(0.89 \%$, wt/vol). A similar upregulation of phlA expression could be observed in the rpoN mutant (data not shown), thus excluding a potential effect of the carbon source. Taken together, these findings demonstrate that RpoN may control the balance of antibiotic production in a biocontrol strain of $P$. fluorescens.

\section{RpoN is essential for biocontrol capacity of $\boldsymbol{P}$. fluorescens.}

The contribution of RpoN to the biocontrol ability of $P$. fluorescens strain $\mathrm{CHA} 0$ against a root rot and damping-off disease of cucumber caused by the pathogenic oomycete Pythium ultimum was tested in natural soil microcosms. P. ultimum severely reduced growth and survival of cucumber plants when no biocontrol bacteria were applied to soil (Table 4). Addition of strain CHA0 to pathogen-infested soil enhanced plant survival by $29 \%$ and plant fresh weights were increased threefold (Table 4). The rpoN mutant CHA250 was severely impaired in its capacity to protect cucumber from the root disease; plant survival and plant fresh weights were only marginally higher than those of plants treated with the pathogen alone (Table 4). Biocontrol activity of the rpoN mutant could be restored by complementing the strain with monocopy rpoN $N^{+}$(Table 4). Overexpression of rpoN from the natural promoter or from the constitutive lac promoter in strains CHA0/pME8013 and CHA0/pME8014, respectively, did not result in a significantly altered biocontrol activity (Table 4). In the absence of the patho- gen, plant growth was not significantly affected by addition of bacteria (Table 4). Remarkably, root colonization levels at the end of the experiment were similar for all bacterial strains and varied between 0.4 and $1.7 \times 10^{7} \mathrm{CFU} / \mathrm{g}$ of roots in the absence of Pythium spp. and between 2.1 and $4.9 \times 10^{7} \mathrm{CFU} / \mathrm{g}$ of roots in pathogen-infested soil. To check whether differences in bacterial root colonization levels occurred eventually at earlier stages of Pythium spp. infection, we determined population densities of the wild-type CHAO and the rpoN mutant CHA250 on cucumber roots also at 2 and 3 days after bacterial application to soil. However, in no case were population densities of the two strains on cucumber roots significantly different in either the presence or absence of the pathogen (data not shown).

\section{DISCUSSION}

In this study, we identified the rpoN locus in the plant-beneficial Pseudomonas fluorescens strain CHA0. The arrangement of rpoN and adjacent genes in P. fluorescens (Fig. 1) is identical to that described for $P$. putida (Köhler et al. 1994), P. stutzeri (Härtig and Zumft 1998), P. aeruginosa (Jin et al. 1994; Stover et al. 2000), and P. syringae (Alarcón-Chaidez and Bender 2001), thus confirming that the gene alignment in this chromosomal region is conserved in different Pseudomonas spp. Our results demonstrate that RpoN of P. fluorescens is

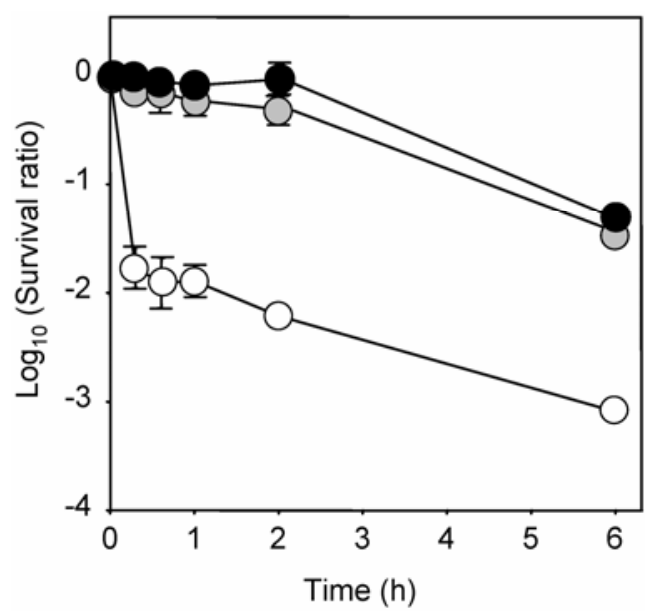

Fig. 3. Survival of Pseudomonas fluorescens wild-type CHA0 (black circle), the rpoN mutant CHA250 (open circle), and the rpoNoverexpressing derivative CHA0/pME8014 (gray-shaded circle) during exposure to $1.2 \mathrm{M} \mathrm{NaCl}$. Survival was expressed as the $\log _{10}$ of the ratio of $\mathrm{CFU}$ in the exposed suspension to the CFU in the initial suspension (Sarniguet et al. 1995). Means \pm standard deviation from three replicate cultures are shown. The experiment was repeated, with similar results. Some of the error bars were too small to be included.

Table 2. Effect of an rpoN mutation on tolerance of Pseudomonas fluorescens to osmotic stress

\begin{tabular}{|c|c|c|c|c|c|c|}
\hline \multirow[b]{2}{*}{ Strain $^{z}$} & \multirow[b]{2}{*}{ Relevant genotype } & \multirow[b]{2}{*}{ Without stress } & \multicolumn{2}{|c|}{ Doubling time $(h)^{x}$} & \multicolumn{2}{|c|}{ Ratio $^{\mathbf{y}}$} \\
\hline & & & $0.6 \mathrm{M} \mathrm{NaCl}$ & 1.2 M Sorbitol & $0.6 \mathrm{M} \mathrm{NaCl}$ & 1.2 M Sorbitol \\
\hline $\mathrm{CHAO}$ & Wild type & $0.74 \mathrm{c}$ & $2.28 \mathrm{~b}$ & $1.51 \mathrm{c}$ & 3.1 & 2.0 \\
\hline CHA250 & $\Delta r p o N$ & $1.09 \mathrm{a}$ & $4.52 \mathrm{a}$ & $2.42 \mathrm{a}$ & 4.2 & 2.2 \\
\hline CHA251 & $\Delta r p o N$ attTn $7:: r p o N^{+}$ & $0.75 \mathrm{c}$ & $2.02 \mathrm{~b}$ & $1.62 \mathrm{bc}$ & 2.7 & 2.2 \\
\hline CHA0/pME8013 & $P_{\mathrm{rpoN}}-r p o N^{+}$ & $0.82 \mathrm{bc}$ & $1.92 \mathrm{~b}$ & $2.06 \mathrm{~b}$ & 2.3 & 2.5 \\
\hline CHA0/pME8014 & $P_{\mathrm{lac}^{-}} \mathrm{rpoN}^{+}$ & $0.86 \mathrm{~b}$ & $1.69 \mathrm{~b}$ & $2.07 \mathrm{~b}$ & 2.0 & 2.4 \\
\hline
\end{tabular}

${ }^{\mathrm{x}}$ Doubling time was calculated from optical density (OD) at $600 \mathrm{~nm}$ values determined during exponential growth phase (eight measurements). During this, the relation of OD at $600 \mathrm{~nm}$ values to CFU counts was linear (data not shown). Data are means from two independent experiments, with three replicate cultures per experiment. Values in the same column with different letters are significantly different at $P=0.05$ (Fisher's least significant difference test).

${ }^{y}$ Ratio denotes the $x$-fold increase in doubling time of stressed $(0.6 \mathrm{M} \mathrm{NaCl}$ or $1.2 \mathrm{M}$ sorbitol) versus nonstressed cultures for each bacterial strain.

${ }^{\mathrm{z}}$ Bacteria were grown at $30^{\circ} \mathrm{C}$ in King's medium B broth with (and without) the addition of $\mathrm{NaCl}$ or sorbitol. 
functionally equivalent to its counterparts in other Pseudomonas spp. with respect to its importance for motility and utilization of various carbon and nitrogen sources (Alarcón-Chaidez et al. 2003; Hendrickson et al. 2000b, 2001; Ishimoto and Lory 1989; Köhler et al. 1989; Merrick 1993; Totten et al. 1990).

We also tested whether RpoN, as well as RpoS (Sarniguet et al. 1995) and AlgU (Schnider-Keel et al. 2001), may be an additional $\sigma$ factor required for tolerance of $P$. fluorescens to environmental stress. Indeed, the rpoN mutant of strain CHA0 was significantly more sensitive to hyperosmotic conditions induced by $\mathrm{NaCl}$ (Table 2; Fig. 3), confirming previous results obtained with an rpoN mutant of $P$. aeruginosa PAO1 (Sage et al. 1997). By contrast, the rpoN mutant of strain CHA0 displayed wild-type sensitivities to agents that generate ROIs. Similarly, an rpoN mutant of $P$. putida KT2440 was reported not to be impaired in its tolerance toward oxidative stress; however, this mutant was not affected in its sensitivity to either salt stress or high temperature (Cases and de Lorenzo 2001).

More intriguingly, our findings provide evidence for novel roles of RpoN as a key regulator of antibiotic production and biocontrol activity in $P$. fluorescens. On the one hand, RpoN was found to positively control the expression of plt biosynthetic genes (Fig. 4B) and PLT production (Fig. 4D) in strain CHA0. Interestingly, RpoN has been reported previously to be essential for the expression of the phytotoxin coronatine in the plantpathogenic bacteria $P$. syringae pv. maculicola (Hendrickson et al. 2000b) and $P$. syringae pv. glycinea (Alarcón-Chaidez et al.
2003). In the same vein, RpoN was required for the production of the antibiotic and virulence factor pyocyanin in $P$. aeruginosa (Hendrickson et al. 2001; Thompson et al. 2003). On the other hand, RpoN exerted a strong negative effect on the expression of phl biosynthetic genes (Fig. 4A) and DAPG production (Fig. 4C) in P. fluorescens CHA0. Recently, a negative effect of RpoN has been reported by Heurlier and associates (2003), who found that mutation of rpoN in $P$. aeruginosa leads to overexpression of $\mathrm{N}$-acyl homoserine lactones and some quorum-sensing-regulated virulence factors such as the biocide hydrogen cyanide, but the precise mechanisms involved remain unknown.

At the current stage, we can only speculate on how RpoN might affect the balance of antibiotic production in $P$. fluorescens $\mathrm{CHA} 0$. We could not detect typical motifs recognized by $\sigma^{54}$ (i.e. YTGGCACR-N4-TTGCW) (Barrios et al. 1999; Reitzer and Schneider 2001; Studholme and Buck 2000) in the phlA and pltA leader regions, suggesting that RpoN does not directly interact with the promoters of the DAPG and PLT biosynthetic genes. However, we could find a potential $\sigma^{54}$-binding

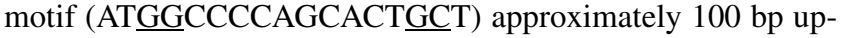
stream of the translational start of pltR (M. Bottiglieri and C. Keel, unpublished data). Because PltR functions as a pathwayspecific activator of PLT gene expression (Haas and Keel 2003; Nowak-Thompson et al. 1999), it seems possible that the positive effect of RpoN on pltA expression is mediated by $\sigma^{54}$-dependent activation of $p l t R$ transcription. Using a transcriptional pltR-lacZ fusion, we have obtained preliminary evi-

Table 3. Bacterial strains and plasmids used in this study

\begin{tabular}{|c|c|c|}
\hline Strain or plasmid & Relevant characteristics ${ }^{\mathrm{z}}$ & Reference or source \\
\hline \multicolumn{3}{|l|}{ Pseudomonas fluorescens } \\
\hline CHA0 & Wild type & Voisard et al. 1994 \\
\hline CHA250 & $\Delta r p o N$ & This study \\
\hline CHA251 & CHA250::att $\operatorname{Tn} 7-r p o N^{+} ; \mathrm{Gm}^{\mathrm{r}}$ & This study \\
\hline CHA815 & $\Delta r p o S$ & Heeb et al. 2002 \\
\hline \multicolumn{3}{|l|}{ Escherichia coli } \\
\hline DH5 $\alpha$, HB101 & Laboratory strains & Sambrook and Russell 2001 \\
\hline \multicolumn{3}{|l|}{ Plasmids } \\
\hline pBluescript II KS+ & Cloning vector; ColE1 replicon; $\mathrm{Ap}^{\mathrm{r}}$ & Stratagene \\
\hline pME497 & Mobilizing plasmid; IncP-1, Tra; RepA(Ts); Ap ${ }^{r}$ & Voisard et al. 1994 \\
\hline pME3087 & Suicide vector; ColE1 replicon; RK2-Mob; $\mathrm{Tc}^{\mathrm{r}}$ & Voisard et al. 1994 \\
\hline pME3280a & $\begin{array}{l}\text { Carrier plasmid for Tn7; containing the mini Tn7-Gm transposon with translational and } \\
\text { transcriptional signals; pUC19ori; } \mathrm{Ap}^{\mathrm{r}} \mathrm{Gm}^{\mathrm{r}}\end{array}$ & $\begin{array}{l}\text { Schnider-Keel et al. 2000; } \\
\text { Zuber et al. } 2003\end{array}$ \\
\hline pME6000 & Cloning vector, $\mathrm{pBBR} 1 \mathrm{MCS}$ derivative; $\mathrm{Tc}^{\mathrm{r}}$ & Schnider-Keel et al. 2001 \\
\hline pME6001 & Cloning vector, $\mathrm{pBBR} 1 \mathrm{MCS}$ derivative; $\mathrm{Gm}^{\mathrm{r}}$ & Valverde et al. 2003 \\
\hline pME6010 & Cloning vector; $\mathrm{pACYC177-pVS1} \mathrm{shuttle} \mathrm{vector;} \mathrm{Tc}^{\mathrm{r}}$ & Heeb et al. 2000 \\
\hline pME6014, pME6015 & Cloning vectors for construction of translational lacZ-fusions; derived from pME6010; $\mathrm{Tc}^{\mathrm{r}}$ & $\begin{array}{l}\text { Schnider-Keel et al. 2000; } \\
\text { this study }\end{array}$ \\
\hline pME6016 & Cloning vector for construction of transcriptional lacZ fusions; derived from pME6010; $\mathrm{Tc}^{\mathrm{r}}$ & Schnider-Keel et al. 2000 \\
\hline pME6182 & $\begin{array}{l}\text { Carrier plasmid for } \mathrm{Tn} 7 \text { containing the mini Tn7-Gm transposon; derived from pME3280a; } \\
\text { multiple cloning site flanked by transcription terminators; } \mathrm{Ap}^{\mathrm{r}} \mathrm{Gm}^{\mathrm{r}}\end{array}$ & C. Reimmann \\
\hline pME6259 & pME6014 carrying a translational phlA'-'lacZ fusion; $\mathrm{Tc}^{\mathrm{r}}$ & Schnider-Keel et al. 2000 \\
\hline pME6551 & Cloning vector; derivative of pME6000; $\mathrm{Gm}^{\mathrm{r}}$ & Schnider-Keel et al. 2001 \\
\hline pME6710 & pME6016 carrying a transcriptional phlA-lacZ fusion; $\mathrm{Tc}^{\mathrm{r}}$ & Schnider-Keel et al. 2000 \\
\hline pME6751 & $\begin{array}{l}\text { pME6015 with a 864-bp pltA upstream fragment and a translational pltA'-'lacZ fusion } \\
\text { containing the first } 43 \text { pltA codons; Tc }{ }^{r}\end{array}$ & This study \\
\hline pME7066 & pME3087 carrying a 867-bp BamHI-HindIII insert with a deletion in $r p o N ; \mathrm{Tc}^{\mathrm{r}}$ & This study \\
\hline pME7069 & $\begin{array}{l}\text { pME6000 with a 2,199-bp BamHI-XbaI fragment containing } r p o N \text { and its flanking regions of } \\
\text { CHA0; Tc }{ }^{\mathrm{r}}\end{array}$ & This study \\
\hline pME7070 & pME6182 with the 1,952-bp BamHI-NcoI fragment of pME7069 containing $r p o N ; \mathrm{Ap}^{\mathrm{r}} \mathrm{Gm}^{\mathrm{r}}$ & This study \\
\hline pME8007 & $\begin{array}{l}\text { pME6016 with a 798-bp pltA upstream fragment and a transcriptional pltA-lacZ fusion } \\
\text { containing the first } 9 \text { pltA codons; } \mathrm{Tc}^{\mathrm{r}}\end{array}$ & This study \\
\hline pME8013 & pME6551 with a 2.2-kb HindIII-EcoRI fragment of pME7070 containing rpoN; $\mathrm{Gm}^{\mathrm{r}}$ & This study \\
\hline pME8014 & $\begin{array}{l}\text { pME6551 with a 1,515-bp fragment derived from pME7070 containing } r p o N \text { and a } \\
\text { 21-bp upstream region placed under the control of the } l a c \text { promoter; } \mathrm{Gm}^{\mathrm{r}}\end{array}$ & This study \\
\hline pNAB 1 & $\begin{array}{l}\text { pBluescript II KS+ with a } 0.86-\mathrm{kb} \text { Pst I-BamHI fragment encompassing the pltR-pltLA } \\
\text { intergenic region }\end{array}$ & This study \\
\hline pUK21 & Cloning vector; $l a c Z \alpha ; \mathrm{Km}^{\mathrm{r}}$ & Vieira and Messing 1991 \\
\hline pUX-BF13 & $\begin{array}{l}\text { Helper plasmid for } \mathrm{Tn} 7 \text {-based transposon mutagenesis containing the transposition functions; } \\
\text { R6K-replicon; } \mathrm{Ap}^{\mathrm{r}}\end{array}$ & Bao et al. 1991 \\
\hline
\end{tabular}

\footnotetext{
${ }^{\mathrm{z}} \mathrm{Ap}^{\mathrm{r}}$, ampicillin resistance; $\mathrm{Gm}^{\mathrm{r}}$, gentamicin resistance; $\mathrm{Km}^{\mathrm{r}}$, kanamycin resistance; $\mathrm{Tc}^{\mathrm{r}}$, tetracycline resistance.
} 
dence that RpoN may function as an activator of pltR transcription (M. Bottiglieri and C. Keel, unpublished data). Analogously, in $P$. syringae, putative $\sigma^{54}$ recognition motifs were localized upstream of the start codon of corR encoding a transcriptional activator of coronatine gene expression, but were not found in the promoter regions of the coronatine biosynthetic genes (Alarcón-Chaidez et al. 2003; Hendrickson et al. 2000b). Surprisingly, a similar plausible $\sigma^{54}$ recognition motif appears to lack in the leader region of phlF (M. Bottiglieri and C. Keel, unpublished findings), which encodes a pathway-specific transcriptional repressor of DAPG gene expression in $P$. fluorescens (Bangera and Thomashow 1999; Delany et al. 2000; Schnider-Keel et al. 2000). PLT is known to strongly repress DAPG gene expression in $P$. fluorescens CHA0 (Schnider-Keel et al. 2000); therefore, it is tempting to speculate that the negative effect of RpoN on phl gene expression may take place indirectly through enhanced production of PLT following $\sigma^{54}$-dependent activation of pltR expression.

However, other regulatory elements might interfere with RpoN-mediated control of antibiotic production as well. A po- tential candidate is the alternative $\sigma$ factor RpoS, which is known to exert an effect on PLT expression that is opposite to that of RpoN. In rpoS mutants of P. fluorescens strains CHA0 and Pf-5, expression of plt biosynthetic genes and PLT production is enhanced severalfold (Haas and Keel 2003; Sarniguet et al. 1995), pointing to the possibility that cellular levels of RpoN and RpoS could influence the relative amounts of this antifungal compound produced by the bacterium. Future work also may include investigations of the potential interactions of RpoN with components of the GacS/GacA signal transduction cascade (Haas and Keel 2003; Valverde et al. 2003; Zuber et al. 2003).

The rpoN mutant of $P$. fluorescens CHA0 had a drastically reduced capacity to protect cucumber plants from Pythium root rot and damping-off disease in natural soil (Table 4), thus establishing RpoN, in addition to RpoD and RpoS, as a further $\sigma$ factor involved in the regulation of biocontrol activity in plantbeneficial pseudomonads. Previous studies have shown that RpoD overexpression or loss of RpoS function enhances the disease suppressive effect of $P$. fluorescens against Pythium spp. on cucumber (Maurhofer et al. 1992; Sarniguet et al. 1995;
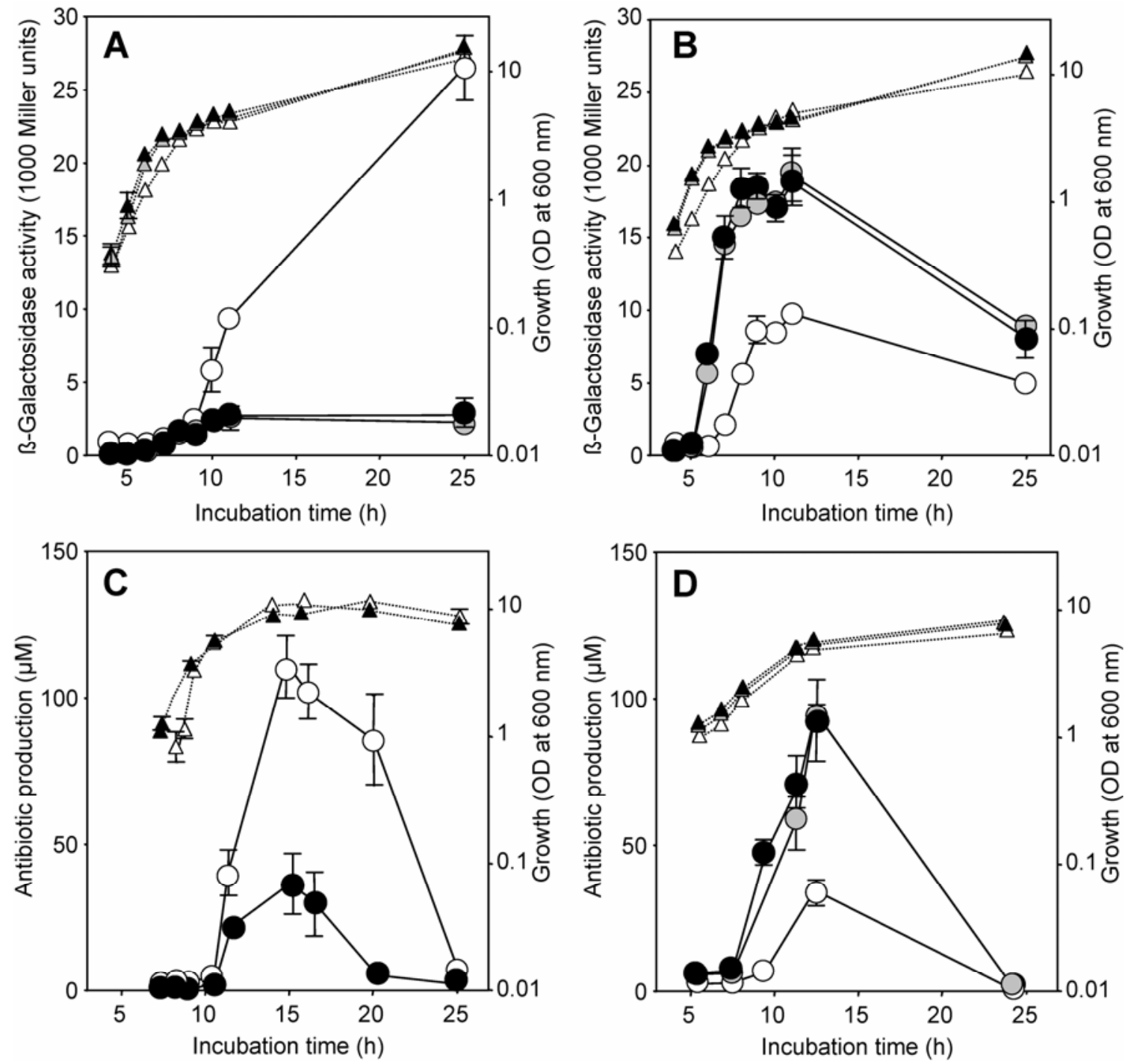

Fig. 4. RpoN control of the biosynthesis of antifungal compounds in Pseudomonas fluorescens strain CHA0. Expression of the plasmid-borne transcriptional reporter fusions $\mathbf{A}$, phlA-lacZ (pME6710) and $\mathbf{B}$, pltA'-lacZ (pME8007) and production of $\mathbf{C}$, 2,4-diacetylphloroglucinol and D, pyoluteorin in growing cultures of wild-type CHA0 (black circle), the $r p o N$ in-frame-deletion mutant CHA250 (open circle), and the $r p o N$ mutant complemented with monocopy rpoN $N^{+}$CHA251 (gray-shaded circle). Specific $\beta$-galactosidase activities and antibiotic production were determined for bacteria cultivated in King's medium B broth at $30^{\circ} \mathrm{C}$. Growth (optical density [OD] at $600 \mathrm{~nm}$ ) of strains CHA0, CHA250, and CHA251 are indicated by black, open, and gray-shaded triangles, respectively. Means \pm standard deviation from three replicate cultures are shown. The experiment was repeated, with similar results. Some of the error bars were too small to be included. 
Schnider et al. 1995), suggesting that a balance between the three $\sigma$ factors may be important for calibrating levels of biocontrol activity. Due to the pleiotropic effects of the rpoN mutation in Pseudomonas fluorescens CHA0, it is difficult to assign the defect in biocontrol efficacy to a certain phenotype of the rpoN mutant. Reduced production of the antifungal compound PLT (Fig. 4D), which has been associated with the suppression of Pythium diseases by $P$. fluorescens (Howell and Stipanovic 1980; Kraus and Loper 1995; Maurhofer et al. 1994), may have accounted, at least partly, for this effect. However, there is the conflicting finding that the rpoN mutant excretes enhanced levels of DAPG (Fig. 4C) and there is some evidence that DAPG also may contribute to Pythium spp. suppression (Maurhofer et al. 1992, 1995; Schnider et al. 1995; M. Péchy-Tarr and C. Keel, unpublished data). However, the actual kinetics of DAPG and PLT expression on plant roots might be significantly different from those observed in vitro. Moreover, because the $r p o N$ mutant shows several defects in nitrogen and carbon source metabolism, it also may be impaired in the utilization of certain root exudates that may be required for effective production of the two antifungal compounds. In pathogenic pseudomonads, deletion of rpoN results in significantly reduced virulence in some animal and plant models, but decreased pathogenicity also could be only partly explained by lowered expression of virulence factors (i.e., certain toxins) by the rpoN mutants (AlarcónChaidez et al. 2003; Hendrickson et al. 2000a,b, 2001). In some cases, decreased virulence of these mutants was associated with defects in their host colonization ability. For instance, rpoN mutants of Pseudomonas aeruginosa and P. syringae showed strongly reduced proliferation in planta (Alarcón-Chaidez et al. 2003; Hendrickson et al. 2000b, 2001) and a P. aeruginosa rpoN mutant was impaired in its capacity to form biofilms on the fungal pathogen Candida albicans (Hogan and Kolter 2002). In contrast, root colonization levels of the P. fluorescens rpoN mutant used in the present study were not significantly different from those of the wild type at different plant growth stages (Table 4; data not shown). Nevertheless, it still is possible that the rpoN mutation could have resulted in altered root colonization patterns at a microniche level, eventually leading to reduced biocontrol efficacy.

At present, it is difficult to explain our finding that overexpression of RpoN has no major effects on the expression of the RpoN-dependent phenotypes described for $P$. fluorescens CHA0 in this study. One possibility is that higher intracellular levels of $\sigma^{54}$ also require higher levels of the different enhancer-binding proteins that are necessary for activation of the $\sigma^{54}$-RNAP complex and, thus, for efficient expression of RpoN-dependent functions (Buck et al. 2000). Alternatively, it is possible that wild-type levels of $\sigma^{54}$ in the cells are already sufficient for effective expression of the RpoN-dependent phenotypes. In $P$. putida and Escherichia coli, intracellular levels of $\sigma^{54}$ remain constant at relatively low levels (compared with the housekeeping $\sigma$ factor $\sigma^{70}$ ) throughout the different growth stages (Jishage et al. 1996; Jurado et al. 2003). This is in agreement with our recent finding that, in $P$. fluorescens wild-type $\mathrm{CHA}$, an rpoN-lacZ reporter fusion was expressed at a very low and constant level throughout bacterial growth (S. Mathys and C. Keel, unpublished data). Remarkably, rpoN expression was enhanced approximately fivefold in the rpoN mutant CHA250, pointing to a mechanism of negative autoregulation of rpoN expression. By contrast, in CHA0 derivatives overexpressing RpoN from the vectors pME8013 and pME8014, rpoN expression was reduced to levels below that of the wild type (S. Mathys and C. Keel, unpublished findings), thus providing a possible explanation for the lack of a significant effect of RpoN overexpression in P. fluorescens. Negative autoregulation of rpoN expression has been reported previously in $P$. putida (Köhler et al. 1994) and several other bacterial species (Buck et al. 2000).

In conclusion, our results confirm the important role of RpoN in bacterial motility and nitrogen and carbon metabolism and establish this $\sigma$ factor for the first time as a major regulator of antibiotic production and biocontrol activity in $P$. fluorescens. However, due to the complex consequences of the rpoN mutation, the exact mechanism of loss of biocontrol activity awaits further elucidation.

\section{MATERIALS AND METHODS}

\section{Microorganisms, plasmids, and culture conditions.}

The bacterial strains and plasmids used in this study are described in Table 3. P. fluorescens strains were cultivated on nutrient agar (NA) (Stanisich and Holloway 1972), on KMB agar (King et al. 1954), in nutrient yeast broth (NYB) (Stanisich and Holloway 1972), in KMB broth, and in LB broth (Sambrook and Russell 2001) at $30^{\circ} \mathrm{C}$ with aeration. $E$. coli strains were grown on NA and in NYB at $37^{\circ} \mathrm{C}$. Antimicrobial compounds, when required, were added to the growth

Table 4. Contribution of RpoN to the suppression of Pythium damping-off and root rot of cucumber by Pseudomonas fluorescens CHA0 in natural soil ${ }^{\mathrm{x}}$

\begin{tabular}{|c|c|c|c|c|c|}
\hline Bacterial strain added ${ }^{y}$ & $\begin{array}{c}\text { Pythium } \\
\text { added }\end{array}$ & $\begin{array}{l}\text { Surviving plants } \\
\text { per flask }(\%)\end{array}$ & $\begin{array}{l}\text { Shoot fresh weight } \\
\text { per flask (g) }\end{array}$ & $\begin{array}{l}\text { Root fresh weight } \\
\text { per flask (g) }\end{array}$ & $\begin{array}{l}\text { Colonization by } P \text {. fluorescens } \\
\quad\left(\log _{10} \text { CFU/g of roots }\right)^{\mathrm{z}}\end{array}$ \\
\hline None & - & $100 \mathrm{a}$ & $2.09 \mathrm{a}$ & $0.46 \mathrm{a}$ & ND \\
\hline CHA0 (wild type) & - & $99 \mathrm{a}$ & $2.12 \mathrm{a}$ & $0.45 \mathrm{a}$ & $6.67 \pm 0.37$ \\
\hline CHA250 $(\Delta r p o N)$ & - & $100 \mathrm{a}$ & $1.92 \mathrm{a}$ & $0.40 \mathrm{~b}$ & $6.55 \pm 0.15$ \\
\hline CHA251 ( $\operatorname{rpoN}$ attTn7::rpoN $\left.N^{+}\right)$ & - & $98 \mathrm{ab}$ & $1.96 \mathrm{a}$ & $0.42 \mathrm{ab}$ & $7.19 \pm 0.24$ \\
\hline CHA0/pME8013 $\left(P_{\text {rpoN }}-r p o N^{+}\right)$ & - & $97 \mathrm{ab}$ & $1.92 \mathrm{a}$ & $0.41 \mathrm{ab}$ & $6.62 \pm 0.10$ \\
\hline CHA0/pME8014 $\left(P_{\text {lac }^{-}-r p o N^{+}}\right)$ & - & $100 \mathrm{a}$ & $2.16 \mathrm{a}$ & $0.49 \mathrm{a}$ & $6.53 \pm 0.02$ \\
\hline None & + & $63 \mathrm{c}$ & $0.52 \mathrm{~d}$ & $0.13 \mathrm{~d}$ & ND \\
\hline CHA0 & + & $92 \mathrm{ab}$ & $1.54 \mathrm{~b}$ & $0.33 \mathrm{c}$ & $7.56 \pm 0.43$ \\
\hline CHA250 & + & $73 \mathrm{c}$ & $0.75 \mathrm{c}$ & $0.18 \mathrm{~d}$ & $7.20 \pm 0.73$ \\
\hline CHA251 & + & $90 \mathrm{~b}$ & $1.43 \mathrm{~b}$ & $0.31 \mathrm{c}$ & $7.30 \pm 0.15$ \\
\hline CHA0/pME8013 & + & $95 \mathrm{ab}$ & $1.61 \mathrm{~b}$ & $0.38 \mathrm{bc}$ & $7.44 \pm 0.16$ \\
\hline CHA0/pME8014 & + & $93 \mathrm{ab}$ & $1.65 \mathrm{~b}$ & $0.33 \mathrm{c}$ & $7.57 \pm 0.48$ \\
\hline
\end{tabular}

${ }^{x}$ Data represent the means from six individual repetitions of the same experimental setup, with 5 to 10 replicates (flasks containing three cucumber plants) per treatment in each experiment. Means within the same column followed by different letters differ significantly at $P=0.05$, according to Fisher's least significant difference test; $\mathrm{ND}=$ not detected.

${ }^{\text {y }}$ P. fluorescens strains were added at $10^{7} \mathrm{CFU} / \mathrm{g}$ of natural soil contained within 200 -ml flasks (60 g of soil per flask), after planting three 72 -h-old, sterilegrown cucumber seedlings per flask. Pythium ultimum was added as a millet-seed inoculum at $2.5 \mathrm{~g} / \mathrm{kg}$ of soil before planting. Plants were harvested after 7 days.

${ }^{\mathrm{z}}$ A derivative of the rhizosphere-stable plasmid pME6010 (Heeb et al. 2000) was introduced into Pseudomonas fluorescens strains to determine their root colonization capacity. 
media at the following concentrations: ampicillin sodium salt, $100 \mu \mathrm{g} / \mathrm{ml}$; chloramphenicol, $25 \mu \mathrm{g} / \mathrm{ml}$; gentamicin sulphate, $10 \mu \mathrm{g} / \mathrm{ml}$; kanamycin sulphate, $25 \mu \mathrm{g} / \mathrm{ml}$; and tetracycline hydrochloride, $25 \mu \mathrm{g} / \mathrm{ml}$ for $E$. coli and $125 \mu \mathrm{g} / \mathrm{ml}$ for $P$. fluorescens strains. When appropriate, 5-bromo-4-chloro-3-indolyl- $\beta$ D-galactoside was incorporated into solid media to monitor $\beta$ galactosidase expression (Sambrook and Russell 2001). P. ultimum strain 67-1 was cultured on malt agar and, for use in plant disease suppression assays, on autoclaved millet seed as described previously (Maurhofer et al. 1992).

\section{DNA manipulations and sequencing.}

Chromosomal DNA of $P$. fluorescens was prepared as described elsewhere (Schnider-Keel et al. 2000). Isolation of pME3087-based plasmids from E. coli was done by alkaline lysis (Sambrook and Russel 2001). All other small- and largescale plasmid preparations were performed with the cetyltrimethylammonium bromide method (Sambrook and Russel 2001) and the Jetstar 2.0 kit (Genomed, Basel, Switzerland), respectively. Standard techniques were used for restriction, agarose gel electrophoresis, generation of blunt ends with T4 DNA polymerase (Roche Diagnostics, Rotkreuz, Switzerland), isolation of DNA fragments from low-melting-point agarose gels, and ligation (Sambrook and Russell 2001; Schnider-Keel et al. 2000, 2001). Restriction fragments were purified from agarose gels using the Qiagen Gel extraction kit (Qiagen, Hombrechtikon, Switzerland). Bacterial cells were transformed with plasmid DNA by electroporation (Schnider-Keel et al. 2000). Southern blotting with Hybond N membranes (Amersham Biosciences, Otelfingen, Switzerland), random-primed DNA labeling with digoxygenin-11-dUTP, hybridization, and detection (Roche Diagnostics) were performed according to the protocols of the suppliers.

Polymerase chain reactions (PCRs) typically were carried out with 1 to $2 \mathrm{U}$ of thermostable DNA polymerase (Expand High Fidelity PCR System, Roche Diagnostics) in a reaction mixture containing 100 to $200 \mathrm{ng}$ of target DNA, $200 \mu \mathrm{M}$ each of the four dNTPs (Roche Diagnostics), $0.5 \mu \mathrm{M}$ each primer, 1 to $3 \mathrm{mM} \mathrm{MgCl}_{2}$, and $1 \times$ PCR buffer (Roche Diagnostics) in a final volume of $20 \mu \mathrm{l}$. For the amplification reaction, an initial denaturation step of $5 \mathrm{~min}$ at $95^{\circ} \mathrm{C}$ was followed by 25 to 30 thermal cycles $\left(1 \mathrm{~min}\right.$ at $95^{\circ} \mathrm{C}, 30 \mathrm{~s}$ at 55 to $60^{\circ} \mathrm{C}$, and 1 to 2 min at $72^{\circ} \mathrm{C}$ ) and a final elongation step of $5 \mathrm{~min}$ at $72^{\circ} \mathrm{C}$.

Nucleotide sequences of PCR-derived constructs were determined on both strands with the Big Dye Terminator Cycle sequencing kit 1.1 (Perkin Elmer, Fremont, CA, U.S.A.) and an ABI Prism 3100 automatic sequencer (Applied Biosystems, Foster City, CA, U.S.A.), and, in part, by Microsynth (Balgach, Switzerland). Nucleotide and deduced amino acid sequences were analyzed with programs of the European Molecular Biology Open Software Suite.

\section{Cloning of the rpoN gene from $P$. fluorescens.}

To amplify the rpoN gene and its surroundings from $P$. fluorescens $\mathrm{CHA} 0$, the degenerate primers $\mathrm{CK}-\mathrm{P} 1$ (5'-CGGGAT CCCGGAAGTBTAYCTGGGBCACGARTTCCG-3') and CKP2 (5'-GCTCTAGAGCTTCACVAGGGAACGGCCGGGGGT CAGG-3') containing artificial restriction sites (underlined) for BamHI and $X b a \mathrm{I}$, respectively, were used. Primers were designed based on the alignment of genomic sequences of strains P. fluorescens Pf0-1, P. syringae pv. glycinea PG4180 (accession number AF283815), P. syringae pv. maculicola ES4326 (accession number AF199600), P. putida KT2440 (accession number X16474), $P$. putida TN2100 (accession number M24916), $P$. aeruginosa PAO1 (accession number AE004860), P. stutzeri MK21 (accession number AJ223088), and A. vinelandii OP (accession number X05888). The PCR amplification yielded a 2.2- $\mathrm{kb}$ band with an annealing temperature of $59^{\circ} \mathrm{C}$. The PCR product was digested with $B a m \mathrm{HI}$ and $\mathrm{Xba \textrm {I }}$ and cloned into vector pME6000 to give pME7069 (Fig. 1; Table 3). The inserts of three of the clones obtained were sequenced to confirm the identity of the cloned fragment.

\section{Construction of an rpoN in-frame-deletion mutant of $P$. fluorescens.}

For the construction of the rpoN mutant CHA250, a 1,212-bp fragment, including the XLINK motif, the helix-turn-helix motif, the RpoN box, and associated motifs (Buck et al. 2000; Merrick 1993) was deleted in-frame in the rpoN gene (Fig. 1) as follows. A 487-bp BamHI-XhoI fragment, including the first 88 codons of $r p o N$, was isolated from pME7069. A 510-bp fragment from pME7069, including the last six codons of rpoN, ORF1, and the start of $p t s N$ (Fig. 1), then was amplified by PCR with primers CK-P3 (5'-GCGCCTTCCCTCGAGCGTAAGCGG-3'), which created an artificial XhoI site (underlined), and CK-P2 (discussed above). The PCR product was trimmed to $380 \mathrm{bp}$ with XhoI-HindIII (Fig. 1). The 487-bp BamHI-XhoI and 380-bp XhoI-HindIII fragments were cloned by a triple ligation into the suicide plasmid pME3087 digested with BamHI-HindIII, giving plasmid pME7066 (Fig. 1). In parallel, the two fragments also were cloned into pUK21 and the insert was checked by sequencing. Plasmid pME6077 then was integrated into the chromosome of strain CHA0 by triparental mating using E. coli HB101/ pME497 as the mobilizing strain (Schnider-Keel et al. 2000, 2001), with selection for tetracycline- and chloramphenicolresistant recombinants. Excision of the vector by a second crossing-over occurred after enrichment for tetracycline-sensitive cells (Schnider-Keel et al. 2000, 2001). The rpoN mutation was verified by PCR and Southern blotting (data not shown).

\section{Complementation of the rpoN mutation by monocopy $\operatorname{rpoN} N^{+}$.}

To complement strain CHA250 ( $\Delta r p o N)$, the rpoN gene was introduced as a single copy into the chromosome using a miniTn7 delivery system described previously (Bao et al. 1991; Schnider-Keel et al. 2000; Zuber et al. 2003). For this purpose, the 1,952-bp BamHI-NcoI fragment of pME7069 (Fig. 1) was cloned into the mini-Tn7-Gm carrier plasmid pME6182, a derivative of pME3280a (Schnider-Keel et al. 2000; Zuber et al. 2003) in which the multiple cloning site is flanked on both sides by transcriptional termination signals. The construct obtained, pME7070 (Fig. 1), and the Tn7 transposition helper plasmid pUX-BF13 (Bao et al. 1991) were co-electroporated into the recipient strain CHA250. The single Tn7-rpoN+ insertion in strain CHA251 was checked by PCR using primers PTn7Gm (5'-GGCGGTAGTTGGGTCGATAT-3') and PTn7glmS (5'-AA CATGGCCAAGTCGGTCACC-3') and by Southern blotting (data not shown).

\section{Overexpression of rpoN in $\boldsymbol{P}$. fluorescens.}

For rpoN overexpression, the CHA0 rpoN gene was cloned into the multicopy vector pME6551 (18 copies per chromosome equivalent in $P$. fluorescens) (Schnider-Keel et al. 2001) and expressed from its natural promoter or the constitutive lac promoter. Plasmid pME8013 (Table 3) was constructed by cloning a 2.2-kb HindIII-EcoRI fragment of pME7070 (Fig. 1) containing rpoN under the control of its own promoter into pME6551. For the construction of pME8014 (Fig. 1), a 1,515bp fragment derived from pME7070 containing the entire rpoN gene and a 21-bp region upstream of its start codon was PCR amplified with primers SM-P1 (5'-CCGGAATTCATA AGGTGTTAAGCCCCTGCC-3') and SM-P2 (5'-CGCGGA TCCCTACATCAACCGCTTACGTTC-3') containing artificial restriction sites (underlined) for EcoRI and BamHI, respect- 
tively. The PCR product was digested with EcoRI and BamHI, ligated in pME6001 cut with the same enzymes, and verified by sequencing. A $1.6-\mathrm{kb} K p n \mathrm{I}-\mathrm{BamHI}$ fragment from the resulting plasmid then was placed under the control of the lac promoter in pME6551 to give pME8014 (Fig. 1).

\section{Construction of transcriptional and translational lacZ fusions to the pltA gene.}

A pltA'-'lacZ translational fusion was constructed as follows. Sequence information available from the very closely related strain $P$. fluorescens Pf-5 (GenBank accession number AF081920) was used to PCR amplify the pltR'-pltL-pltA' chromosomal region of CHA0 encompassing the promoter region of the pyoluteorin biosynthetic genes, which is located in the intergenic region between pltR and pltL (Nowak-Thompson et al. 1999). Primers CGB-P1 (5'-AACTGCAGAGGTGGGATG CCAAGTAGTC-3') and CGB-P2 (5'-CGGGATCCCATGCTC GCGCTCGAACAGTT-3'), containing artificial restriction sites (underlined) for PstI and BamHI, respectively, served to amplify an 864-bp upstream region and the first 43 codons of the pltA gene. The PCR product was cloned into pBluescript II KS+ giving pNAB1 and the insert was sequenced on both strands. The nucleotide sequence (accession number AY459536) showed $99.8 \%$ identity to the corresponding sequence of $P$. fluorescens Pf-5. A 994-bp EcoRI-BamHI fragment from pNAB1 then was fused in-frame with the 'lacZ gene in vector pME6015 (Table 3), to give the $p l t A^{\prime}$ - $^{\prime}$ lacZ reporter pME6751 (Table 3). The fusion was checked by sequencing.

For the construction of the pltA-lacZ transcriptional fusion, a fragment encompassing a 798-bp upstream region and the first nine codons of the pltA gene was amplified by PCR with primers MB-P14 (5'GGAATTCGTCTATGTCATTGACAACG CCTAGCGCCTTCATTC-3'; artificial EcoRI site underlined) and MB-P15 (5'-CGGGATCCTTACACTACATCATCATAAT CATGATCGCTCATTGCC-3'; artificial BamHI site underlined). The PCR product was cloned into the vector pUK21 and the construct was sequenced on both strands. The 825-bp EcoRI-BamHI fragment from the pUK21 derivative carrying pltR'-pltL-pltA' then was fused to lacZ in plasmid pME6016 (Schnider-Keel et al. 2000), producing the pltA-lacZ reporter pME8007 (Table 3).

\section{Assessment of growth characteristics of the $P$. fluorescens rpoN mutant.}

Growth rates for $P$. fluorescens $\mathrm{CHA} 0$ and its mutant derivatives were assessed by growing the strains at $30^{\circ} \mathrm{C}$ in different rich media, including NYB, LB broth, KMB broth, and GCM (Schnider-Keel et al. 2000), as well as in OSG (Schnider-Keel et al. 2000). Nitrogen source utilization tests were performed in tubes containing $2 \mathrm{ml}$ of M9 salts minimal medium (Sambrook and Russell 2001) with $0.4 \%$ glucose (wt/vol) by replacing or complementing $\mathrm{NH}_{4} \mathrm{Cl}$ with an alternative nitrogen source at 10 $\mathrm{mM}$ when required. After inoculation of the media with aliquots of $20 \mu \mathrm{l}$ of a suspension of washed bacterial cells adjusted to an optical density (OD) of 1.0, cultures were incubated for $24 \mathrm{~h}$ at $30^{\circ} \mathrm{C}$ with shaking at $180 \mathrm{rpm}$ and growth was determined by recording OD at $600 \mathrm{~nm}$ values. In addition, carbon source utilization profiles of wild-type $\mathrm{CHA} 0$ and its $r p o N$ mutant were compared by growing the strains in Biolog GN2 and Biolog GP2 microplates (Biolog Inc., Hayward, CA) containing 128 different carbon sources, including sugars, amino acids, and organic acids (Wang et al. 2001). Bacterial cell suspensions were prepared from LB overnight cultures grown at $30^{\circ} \mathrm{C}$. Cells were washed twice in sterile distilled water and cell density was adjusted to an OD at $600 \mathrm{~nm}$ of 0.25 . The Biolog GN2 and GP2 plates were inoculated with aliquots of $150 \mu \mathrm{l}$ of the bacterial suspension per well and were incubated at $30^{\circ} \mathrm{C}$ for $24 \mathrm{~h}$ with shaking $(500 \mathrm{rpm})$ in a Thermostar incubator (BMG Labtechnologies, Offenburg, Germany). Bacterial growth was determined by measuring OD at $595 \mathrm{~nm}$ with a Fluostar Galaxy microplate reader (BMG Labtechnologies) and wells were scored positive for growth when OD readings exceeded those of control wells that did not contain a carbon source by at least 0.35 . The experiment was repeated twice.

\section{Motility assays.}

Swimming, swarming, and twitching motility of $P$. fluorescens $\mathrm{CHA} 0$ and its derivatives was tested following the procedures described by Rashid and Kornberg (2000). Flagellar swimming was tested on plates containing $0.3 \%$ agar (Serva, Heidleberg, Germany), yeast extract at $10 \mathrm{~g} /$ liter (Difco, Detroit), tryptone at $10 \mathrm{~g} / \mathrm{liter}$ (Difco), and $\mathrm{NaCl}$ at $12.5 \mathrm{~g} / \mathrm{liter}$. Swarming motility was examined on plates containing $0.5 \%$ agar, nutrient broth at $8 \mathrm{~g} /$ liter (Difco), and glucose at $5 \mathrm{~g} /$ liter. Twitching motility was assayed on LB broth solidified with $1 \%$ agar. Cells from bacterial overnight cultures on NA were inoculated into the center of the swim and swarm plates using a sterile toothpick. Plates were incubated for $24 \mathrm{~h}$ at room temperature prior to the assessment of the diameter of bacterial displacement. For twitch plates, cells were stab inoculated with a toothpick to the bottom of the petri dish. After incubation for 4 to 5 days at room temperature, the agar was carefully removed and the bacterial cells attached to the bottom of the petri dish were stained with crystal violet $(1 \%, \mathrm{wt} / \mathrm{vol})$. In all assays, motility was scored as the diameter of bacterial displacement from the point of inoculation.

\section{Transmission electron microscopy.}

Cells from the edge of a colony grown on swarm plates were deposited with a toothpick on a drop of water. Carbon-filmcoated transmission electron microscopy grids were placed on top of the drop for 15 to $20 \mathrm{~s}$ to allow for adhesion of bacterial cells. Grids then were stained with $2 \%$ (wt/vol) potassium phosphotungstic acid (pH 3.0) for 20 to $30 \mathrm{~s}$ and washed for $20 \mathrm{~s}$ in a drop of water. The grids were allowed to air dry and then were examined with a Philips CM12 transmission electron microscope (Heindoven, The Netherlands) at 60 to $80 \mathrm{keV}$. Electron micrographs were taken at a magnification of $\times 10,000$. At least 15 fields of view were analyzed for each sample.

\section{Assays for sensitivity \\ of $\boldsymbol{P}$. fluorescens to osmotic and oxidative stress.}

$P$. fluorescens $\mathrm{CHA} 0$ and its mutant derivatives were grown in $20 \mathrm{ml}$ of KMB broth without selective antibiotics in 100-ml Erlenmeyer flasks plugged with cotton stoppers. To induce conditions of osmotic stress which still allow growth of $P$. fluorescens, KMB was supplemented with $0.6 \mathrm{M} \mathrm{NaCl}, 0.8 \mathrm{M} \mathrm{NaCl}$, or 1.2 $\mathrm{M}$ sorbitol, a nonionic solute which cannot be metabolized by strain CHA0. For inoculation, aliquots of exponentialgrowth-phase LB cultures of the bacterial strains were used to adjust the cell density to an OD at $600 \mathrm{~nm}$ of 0.05 . Cultures were incubated with rotational shaking $(180 \mathrm{rpm})$ at $30^{\circ} \mathrm{C}$. Doubling times of strain $\mathrm{CHA} 0$ and its derivatives were calculated from OD at $600 \mathrm{~nm}$ values between 0.05 and 1.5 (i.e. during exponential growth) (Schnider-Keel et al. 2001).

Susceptibility to oxidative stress was tested by exposing bacterial cells to paraquat, hydrogen peroxide $\left(\mathrm{H}_{2} \mathrm{O}_{2}\right)$, or sodium hypochlorite $(\mathrm{NaOCl})$ as described previously (Schnider-Keel et al. 2001). Sterile filter disks (6-mm diameter; Millipore, Volketswil, Switzerland) were soaked with $10 \mu \mathrm{l}$ of paraquat (1.9 or $3.8 \%$; wt/vol), $\mathrm{H}_{2} \mathrm{O}_{2}$ (3 or $12 \%$; vol/vol), or $\mathrm{NaOCl}(5$ or $10 \%$; vol/vol) and placed on a layer of soft agar $(2 \mathrm{ml}$ of NYB with $0.8 \%$ agar) containing $100 \mu \mathrm{l}$ of an LB overnight culture covering NA. The diameter of the inhibition zone sur- 
rounding the impregnated disks was measured after overnight incubation at $30^{\circ} \mathrm{C}$.

To assess survival in response to osmotic or oxidative stress, stationary-phase cells were washed and suspended in $10 \mathrm{ml}$ of distilled $\mathrm{H}_{2} \mathrm{O}$ to obtain an $\mathrm{OD}$ at $600 \mathrm{~nm}$ of 1.0. Suspended cells were exposed to $1.2 \mathrm{M} \mathrm{NaCl}, 2.4 \mathrm{M}$ sorbitol, or $30 \mathrm{mM}$ $\mathrm{H}_{2} \mathrm{O}_{2}$ (i.e., conditions which no longer allowed growth of $P$. fluorescens) and incubated at $30^{\circ} \mathrm{C}$ with shaking. Cell culturability was determined at different intervals by plating serial dilutions of the cultures on NA.

Assay for expression of DAPG and PLT biosynthetic genes.

$P$. fluorescens $\mathrm{CHA} 0$ and its mutant derivatives carrying a transcriptional phlA-lacZ fusion on plasmid pME6710, a translational phlA' - lacZ fusion on pME6259, a transcriptional pltAlac $Z$ fusion on $\mathrm{pME8007,} \mathrm{or} \mathrm{a} \mathrm{translational} \mathrm{pltA'} \mathrm{-} \mathrm{lacZ} \mathrm{fusion} \mathrm{on}$ pME6715 (Table 3) were grown in $20 \mathrm{ml}$ of KMB broth without selective antibiotics using 100-ml Erlenmeyer flasks sealed with cellulose stoppers. For inoculation, $200 \mu$ of a suspension of washed cells (OD at $600 \mathrm{~nm}$ adjusted to 2) from overnight KMB broth cultures of the bacterial strains were used. Cultures were incubated at $30^{\circ} \mathrm{C}$ with rotational shaking at $180 \mathrm{rpm}$, and $\beta$-galactosidase-specific activities of at least three independent cultures were determined by the method of Miller (Sambrook and Russell 2001). The experiment was done twice.

\section{Quantification of DAPG and PLT production.}

Production of DAPG and PLT was assessed for bacteria grown in 500-ml Erlenmeyer flasks with $100 \mathrm{ml}$ of KMB broth. For inoculation, 1-ml aliquots of overnight cultures of the bacterial strains grown in $\mathrm{KMB}$ broth at $30^{\circ} \mathrm{C}$ and adjusted to an OD at $600 \mathrm{~nm}$ of 2.0 were used. Cultures were incubated at $30^{\circ} \mathrm{C}$ with rotational shaking at $180 \mathrm{rpm}$. DAPG and PLT were extracted with ethyl acetate from acidified culture supernatants and quantified by established high-performance liquid chromatography procedures as described before (Keel et al. 1992; Maurhofer et al. 1992, 1994). The experiment was repeated twice.

\section{Plant disease suppression and root colonization assays.}

For the plant assays, aliquots of $60 \mathrm{~g}$ of natural sandy loam soil from Eschikon, Switzerland (Keel et al. 2002) were distributed into 200-ml Erlenmeyer flasks with wide openings. When appropriate, the soil was artificially infested with the pathogenic oomycete $P$. ultimum $67-1$ by adding $2.5 \mathrm{~g}$ of a 5day-old millet-seed inoculum (Maurhofer et al. 1992; Keel et al. 2002) of the pathogen per kilogram of soil. Three sterilegrown, 72-h-old cucumber seedlings (Cucumis sativus cv. Chinese Snake) then were placed in each flask as previously described (Keel et al. 2002). P. fluorescens strains were added to soil as a suspension ( $5 \mathrm{ml}$ per flask) of cells washed twice in sterile distilled water to give $1 \times 10^{7} \mathrm{CFU} / \mathrm{g}$ of soil. Control flasks received the same amount of sterile water. Seedlings were covered with $10 \mathrm{~g}$ of nontreated soil and flasks were sealed with cotton stoppers. The microcosms were incubated in a randomized block design in a growth chamber containing $80 \%$ relative humidity and $22^{\circ} \mathrm{C}$ with light $\left(200 \mu \mathrm{mol} \mathrm{sec} \mathrm{m}^{-1}\right.$ 2; ratio of 1.37 of light at 660 to $730 \mathrm{~nm}$ ) for $16 \mathrm{~h}$, followed by an 8 -h dark period at $15^{\circ} \mathrm{C}$. No watering was necessary. At 6 days after inoculation, the percentage of surviving plants was determined. Plants were removed from the flasks, washed, briefly dried with paper towels, and weighed. Roots from each flask were pooled and transferred into 50-ml plastic tubes containing $20 \mathrm{ml}$ of sterile distilled water. Tubes were vigorously shaken at $240 \mathrm{rpm}$ for $30 \mathrm{~min}$ and the resulting suspensions were used to determine CFU numbers. In a subset of experiments, root colonization also was determined at 2 and 3 days after bacterial inoculation. Data represent the means from six individual repetitions of the same experiment with 5 to 10 replicates per treatment in each experiment (1 replicate corresponds to one flask containing three cucumber plants). Data were analyzed for significance with variance analysis, followed by Fisher's least significant difference test. Data for CFU counts were $\log _{10}$-transformed prior to statistical analysis.

\section{ACKNOWLEDGMENTS}

We thank C. Gigot-Bonnefoy, B. Wackwitz, V. Dénervaud, N. Burger, F. Adamer, N. Wenger, C. Genoud, and P. Michaux for help with some of the experiments; M. Adrian (Laboratoire d'Analyse ultrastructurale, Université de Lausanne) for electron microscopy; and the Swiss National Foundation for Scientific Research (project 3100-061360.00/1) and the Swiss Federal Office of Education and Science (project C99.0032, European COST action 830) for their support.

\section{LITERATURE CITED}

Alarcón-Chaidez, F. J., and Bender, C. L. 2001. Analysis of the rpoN locus in the plant pathogenic bacterium Pseudomonas syringae pv. glycinea. DNA Seq. 12:77-84.

Alarcón-Chaidez, F. J., Keith, L., Zhao, Y., and Bender, C. L. 2003. RpoN $\left(\sigma^{54}\right)$ is required for plasmid-encoded coronatine biosynthesis in Pseudomonas syringae. Plasmid 49:106-117.

Bangera, M. G., and Thomashow, L. S. 1999. Identification and characterization of a gene cluster for synthesis of the polyketide antibiotic 2,4diacetylphloroglucinol from Pseudomonas fluorescens Q2-87. J. Bacteriol. 181:3155-3163.

Bao, Y., Lies, D. P., Fu, H., and Roberts, G. P. 1991. An improved Tn7based system for the single-copy insertion of cloned genes into chromosomes of gram-negative bacteria. Gene 109:167-168.

Barrios, H., Valderrama, B., and Morett, E. 1999. Compilation and analysis of $\sigma^{54}$-dependent promoter sequences. Nucleic Acids Res. 72:43054313.

Boucher, J. C., Schurr, M. J., and Deretic, V. 2000. Dual regulation of mucoidy in Pseudomonas aeruginosa and sigma factor antagonism. Mol. Microbiol. 36:341-351.

Brodhagen, M., Henkels, M. D., and Loper, J. E. 2004. Positive autoregulation and signaling properties of pyoluteorin, an antibiotic produced by the biological control organism Pseudomonas fluorescens Pf-5. Appl. Environ. Microbiol. 70:1758-1766.

Buck, M., Gallegos, M. T., Studholme, D. J., Guo, Y. L., and Gralla, J. D. 2000. The bacterial enhancer-dependent $\sigma^{54}\left(\sigma^{\mathrm{N}}\right)$ transcription factor. J. Bacteriol. 182:4129-4136.

Cases, I., and de Lorenzo, V. 2001. The limits to genomic predictions: role of $\sigma^{\mathrm{N}}$ in environmental stress survival of Pseudomonas putida. FEMS Microbiol. Ecol. 35:217-221.

Cases, I., Pérez-Martín, J., and de Lorenzo, V. 1999. The IIA ${ }^{\mathrm{Ntr}}$ (PtsN) protein of Pseudomonas putida mediates the $\mathrm{C}$ source inhibition of the $\sigma^{54}$ dependent $P u$ promoter of the TOL plasmid. J. Biol. Chem. 274:1556215568.

Cases, I., Ussery, D. W., and de Lorenzo, V. 2003. The $\sigma^{54}$ regulon (sigmulon) of Pseudomonas putida. Environ. Microbiol. 5:1281-1293.

Chatterjee, A., Cui, Y., Yang, H., Collier, A., Alfano, J. R., and Chatterjee, A. K. 2003. GacA, the response regulator of a two-component system, acts as a master regulator in Pseudomonas syringae pv. tomato DC3000 by controlling regulatory RNA, transcriptional activators and alternate sigma factors. Mol. Plant-Microbe Interact. 16:1106-1117.

Cook, R. J., Thomashow, L. S., Weller, D. M., Fujimoto, D., Mazzola, M., Bangera, G., and Kim, D. 1995. Molecular mechanisms of defense by rhizobacteria against root disease. Proc. Natl. Acad. Sci. U.S.A. 92:4197-4201.

Delany, I., Sheehan, M. M., Fenton, A., Bardin, S., Aarons, S., and O'Gara, F. 2000. Regulation of production of the antifungal metabolite 2,4-diacetylphloroglucinol in Pseudomonas fluorescens F113: genetic analysis of $p h l F$ as a transcriptional repressor. Microbiology 146:537546.

Duffy, B. K., and Défago, G. 1999. Environmental factors modulating antibiotic and siderophore biosynthesis by Pseudomonas fluorescens biocontrol strains. Appl. Environ. Microbiol. 65:2429-2438.

Haas, D., Blumer, C., and Keel, C. 2000. Biocontrol ability of fluorescent pseudomonads genetically dissected: importance of positive feedback regulation. Curr. Opin. Biotechnol. 11:290-297.

Haas, D., and Keel, C. 2003. Regulation of antibiotic production in rootcolonizing Pseudomonas spp. and relevance for biological control of plant disease. Annu. Rev. Phytopathol. 41:117-153. 
Härtig, E., and Zumft, W. G. 1998. The requirement of RpoN (sigma factor $\sigma^{54}$ ) in denitrification by Pseudomonas stutzeri is indirect and restricted to the reduction of nitrite and nitric oxide. Appl. Environ. Microbiol. 64:3092-3095

Heeb, S., Blumer, C., and Haas, D. 2002. Regulatory RNA as mediator in GacA/RsmA-dependent global control of exoproduct formation in Pseudomonas fluorescens CHA0. J. Bacteriol. 184:1046-1056.

Heeb, S., Itoh, Y., Nishijyo, T., Schnider, U., Keel, C., Wade, J., Walsh, U., O'Gara, F., and Haas, D. 2000. Small, stable shuttle vectors based on the minimal pVS1 replicon for use in gram-negative, plant-associated bacteria. Mol. Plant-Microbe Interact. 13:232-237.

Hendrickson, E. L., Guevera, P., and Ausubel, F. M. 2000a. The alternative sigma factor RpoN is required for hrp activity in Pseudomonas syringae pv. maculicola and acts at the level of hrpL transcription. J. Bacteriol. 182:3508-3516.

Hendrickson, E. L., Guevera, P., Peñaloza-Vazquez, A., Shao, J., Bender, C., and Ausubel, F. M. 2000b. Virulence of the phytopathogen Pseudomonas syringae pv. maculicola is rpoN dependent. J. Bacteriol. 182:3498-3507.

Hendrickson, E. L., Plotnikova, J., Mahajan-Miklos, S., Rahme, L. G., and Ausubel, F. M. 2001. Differential roles of the Pseudomonas aeruginosa PA14 rpoN gene in pathogenicity in plants, nematodes, insects, and mice. J. Bacteriol. 183:7126-7134.

Heurlier, K., Dénervaud, V., Pessi, G., Reimmann, C., and Haas, D. 2003. Negative control of quorum sensing by RpoN $\left(\sigma^{54}\right)$ in Pseudomonas aeruginosa PAO1. J. Bacteriol. 185:2227-2235.

Hogan, D. A., and Kolter, R. 2002. Pseudomonas-Candida interactions: An ecological role for virulence factors. Science 296:2229-2232.

Howell, C. R., and Stipanovic, R. D. 1980. Suppression of Pythium ultimum-induced damping-off of cotton seedlings by Pseudomonas fluorescens and its antibiotic, pyoluteorin. Phytopathology 70:712-715.

Ishimoto, K. S., and Lory, S. 1989. Formation of pilin in Pseudomonas aeruginosa requires the alternative sigma factor (RpoN) of RNA polymerase. Proc. Natl. Acad. Sci. U.S.A. 86:1954-1957.

Jin, S., Ishimoto, K., and Lory, S. 1994. Nucleotide sequence of the rpoN gene and characterization of two downstream open reading frames in Pseudomonas aeruginosa. J. Bacteriol. 176:1316-1322.

Jishage, M., Iwata, A., Ueda, S., and Ishihama, A. 1996. Regulation of RNA polymerase sigma subunit synthesis in Escherichia coli: intracellular levels of four species of sigma subunit under various growth conditions. J. Bacteriol. 178:5447-5451.

Jurado, P., Fernandez, L. A., and de Lorenzo, V. 2003. Sigma 54 levels and physiological control of the Pseudomonas putida $\mathrm{Pu}$ promoter. J. Bacteriol. 185:3379-3383.

Keel, C., and Défago, G. 1997. Interactions between beneficial soil bacteria and root pathogens: mechanisms and ecological impact. Pages 27-46 in: Multitrophic Interactions in Terrestrial Systems. A. C. Gange and V. K. Brown, eds. Blackwell Science, London.

Keel, C., Schnider, U., Maurhofer, M., Voisard, C., Laville, J., Burger, U., Wirthner, P., Haas, D., and Défago, G. 1992. Suppression of root diseases by Pseudomonas fluorescens CHA0: importance of the bacterial secondary metabolite 2,4-diacetylphloroglucinol. Mol. Plant-Microbe Interact. 5:4-13

Keel, C., Ucurum, Z., Michaux, M., Adrian, M., and Haas, D. 2002. Deleterious impact of a virulent bacteriophage on survival and biocontrol activity of Pseudomonas fluorescens strain CHA0 in natural soil. Mol. Plant-Microbe Interact. 15:567-576.

Keel, C., Weller, D. M., Natsch, A., Défago, G., Cook, R. J., and Thomashow, L. S. 1996. Conservation of the 2,4-diacetylphloroglucinol biosynthesis locus among fluorescent Pseudomonas strains from diverse geographic locations. Appl. Environ. Microbiol. 62:552-563.

Keel, C., Wirthner, P., Oberhänsli, T., Voisard, C., Burger, U., Haas, D. and Défago, G. 1990. Pseudomonads as antagonists of plant pathogens in the rhizosphere: Role of the antibiotic 2,4-diacetylphloroglucinol in the suppression of black root rot of tobacco. Symbiosis 9:327-341.

King, E. O., Ward, M. K., and Raney, D. E. 1954. Two simple media for the demonstration of pyocyanin and fluorescein. J. Lab. Clin. Med. 44:301-307.

Köhler, T., Alvarez, J. F., and Harayama, S. 1994. Regulation of the rpoN, ORF102 and ORF154 genes in Pseudomonas putida. FEMS (Fed. Eur. Microbiol. Soc.) Microbiol. Lett. 115:177-184.

Köhler, T., Curty, L. K., Barja, F., van Delden, C., and Pechère, J. C. 2000 Swarming of Pseudomonas aeruginosa is dependent on cell-to-cell signaling and requires flagella and pili. J. Bacteriol. 182:5990-5996.

Köhler, T., Harayama, S., Ramos, J. L., and Timmis, K. N. 1989. Involvement of Pseudomonas putida RpoN sigma factor in regulation of various metabolic functions. J. Bacteriol. 171:4326-4333.

Kraus, J., and Loper, J. E. 1995. Characterization of a genomic region required for production of the antibiotic pyoluteorin by the biological control agent Pseudomonas fluorescens Pf-5. Appl. Environ. Microbiol.
61:849-854.

Maurhofer, M., Baehler, E., Notz, R., Martinez, V., and Keel, C. 2004 Cross talk between 2,4-diacetylphloroglucinol-producing biocontrol pseudomonads on wheat roots. Appl. Environ. Microbiol. 70:19901998.

Maurhofer, M., Keel, C., Haas, D., and Défago, G. 1994. Pyoluteorin production by Pseudomonas fluorescens strain CHAO is involved in the suppression of Pythium damping-off of cress but not of cucumber. Eur. J. Plant Pathol. 100:221-232.

Maurhofer, M., Keel, C., Haas, D., and Défago, G. 1995. Influence of plant species on disease suppression by Pseudomonas fluorescens strain CHA0 with enhanced antibiotic production. Plant Pathol. 44:40-50.

Maurhofer, M., Keel, C., Schnider, U., Voisard, C., Haas, D., and Défago, G. 1992. Influence of enhanced antibiotic production in Pseudomonas fluorescens strain CHA0 on its disease suppressive capacity. Phytopathology 82:190-195.

Merrick, M. J. 1993. In a class of its own-The RNA polymerase sigma factor $\sigma^{54}\left(\sigma^{\mathrm{N}}\right)$. Mol. Microbiol. 10:903-909.

Michiels, J., Van Soom, T., D’Hooghe, I., Dombrecht, B., Benhassine, T., de Wilde, P., and Vanderleyden, J., 1998. The Rhizobium etli rpoN locus: DNA sequence analysis and phenotypical characterization of rpoN, pts $N$, and ptsA mutants. J. Bacteriol. 180:1729-1740.

Notz, R., Maurhofer, M., Schnider-Keel, U., Duffy, B., Haas, D., and Défago, G. 2001. Biotic factors affecting expression of the 2,4-diacetylphloroglucinol biosynthesis gene phlA in Pseudomonas fluorescens biocontrol strain CHA0 in the rhizosphere. Phytopathology 91:873881.

Nowak-Thompson, B., Chaney, N., Wing, J. S., Gould, S. J., and Loper, J. E. 1999. Characterization of the pyoluteorin biosynthetic gene cluster of Pseudomonas fluorescens Pf-5. J. Bacteriol. 181:2166-2174.

Raaijmakers, J. M., Vlami, M., and de Souza, J. T. 2002. Antibiotic production by bacterial biocontrol agents. Antonie van Leeuwenhoek Int. J. Gen. Mol. Microbiol. 81:537-547.

Rashid, M. H., and Kornberg, A. 2000. Inorganic polyphosphate is needed for swimming, swarming, and twitching motilities of Pseudomonas aeruginosa. Proc. Natl. Acad. Sci. U.S.A. 97:4885-4890.

Reitzer, L., and Schneider, B. L. 2001. Metabolic context and possible physiological themes of $\sigma^{54}$-dependent genes in Escherichia coli. Microbiol. Mol. Biol. Rev. 65:422-444.

Sage, A. E., Vasil, A. I., and Vasil, M. L. 1997. Molecular characterization of mutants affected in the osmoprotectant-dependent induction of phospholipase C in Pseudomonas aeruginosa PAO1. Mol. Microbiol. 23:4356.

Sambrook, J., and Russell, D. W. 2001 Molecular Cloning: A Laboratory Manual, 3rd ed. Cold Spring Harbor Laboratory Press, Cold Spring Harbor, NY, U.S.A

Sarniguet, A., Kraus, J., Henkels, M. D., Muehlchen, A. M., and Loper, J. E. 1995. The sigma factor $\sigma^{\mathrm{S}}$ affects antibiotic production and biological control activity of Pseudomonas fluorescens Pf-5. Proc. Natl. Acad. Sci. U.S.A. 92:12255-12259.

Schnider, U., Keel, C., Blumer, C., Troxler, J., Défago, G., and Haas, D. 1995. Amplification of the house-keeping sigma factor in Pseudomonas fluorescens $\mathrm{CHA} 0$ enhances antibiotic production and improves biocontrol abilities. J. Bacteriol. 177:5387-5392.

Schnider-Keel, U., Bang Lejbølle, K., Baehler, E., Haas, D., and Keel, C. 2001. The sigma factor $\mathrm{AlgU}(\mathrm{AlgT})$ controls exopolysaccharide production and tolerance towards desiccation and osmotic stress in the biocontrol agent Pseudomonas fluorescens CHA0. Appl. Environ. Microbiol. 67:5683-5693.

Schnider-Keel, U., Seematter, A., Maurhofer, M., Blumer, C., Duffy, B. Gigot-Bonnefoy, C., Reimmann, C., Notz, R., Défago, G., Haas, D., and Keel, C. 2000 Autoinduction of 2,4-diacetylphloroglucinol biosynthesis in the biocontrol agent Pseudomonas fluorescens $\mathrm{CHA} 0$ and repression by the bacterial metabolites salicylate and pyoluteorin. J. Bacteriol. 182:1215-1225.

Stanisich, V. A., and Holloway, B. W. 1972. A mutant sex factor of Pseudomonas aeruginosa. Genet. Res. 19:91-108.

Stover, C. K., Pham, X. Q., Erwin, A. L., Mizoguchi, S. D., Warrener, P., Hickey, M. J., Brinkman, F. S., Hufnagle, W. O., Kowalik, D. J., Lagrou, M., Garber, R. L., Goltry, L., Tolentino, E., Westbrock-Wadman, S., Yuan, Y., Brody, L. L., Coulter, S. N., Folger, K. R., Kas, A., Larbig, K., Lim, R., Smith, K., Spencer, D., Wong, G. K., Wu, Z., Paulsen, I. T. Reizer, J., Saier, M. H., Hancock, R. E., Lory, S., and Olson, M. V. 2000. Complete genome sequence of Pseudomonas aeruginosa PAO1, an opportunistic pathogen. Nature 406:959-964.

Studholme, D. J., and Buck, M. 2000. The biology of enhancer-dependent transcriptional regulation in bacteria: insights from genome sequences. FEMS (Fed. Eur. Microbiol. Soc.) Microbiol. Lett. 186:1-9.

Thomashow, L. S., and Weller, D. M. 1995. Current concepts in the use of introduced bacteria for biological disease control. Pages 187-235 in: 
Plant-Microbe Interactions, Vol. 1. G. Stacey and N. Keen, eds. Chapman and Hall, Inc., New York.

Thompson, L. S., Webb, J. S., Rice, S. A., and Kjelleberg, S. 2003. The alternative sigma factor RpoN regulates the quorum sensing gene rhlI in Pseudomonas aeruginosa. FEMS (Fed. Eur. Microbiol. Soc.) Microbiol. Lett. 220:187-195.

Totten, P. A., Lara, J. C., and Lory, S. 1990. The rpoN gene product of Pseudomonas aeruginosa is required for expression of diverse genes, including the flagellin gene. J. Bacteriol. 172:389-396.

Valverde, C., Heeb, S., Keel, C., and Haas, D. 2003. RsmY, a small regulatory RNA, is required in concert with RsmZ for GacA-dependent expression of biocontrol traits in Pseudomonas fluorescens CHA0. Mol. Microbiol. 50:1361-1379.

Vieira, J., and Messing, J. 1991. New pUC-derived cloning vectors with different selectable markers and DNA replication origins. Gene 100:189-194

Voisard, C., Bull, C., Keel, C., Laville, J., Maurhofer, M., Schnider, U., Défago, G., and Haas, D. 1994. Biocontrol of root diseases by Pseudomonas fluorescens $\mathrm{CHA} 0$ : Current concepts and experimental approaches. Pages 67-89 in: Molecular Ecology of Rhizosphere Microorganisms. F.
O'Gara, D. Dowling, and B. Boesten, eds. VCH Publishers, Weinheim, Germany.

Wang, C., Ramette, A., Punjasamarnwong, P., Zala, M., Natsch, A. Moënne-Loccoz, Y., and Défago, G. 2001. Cosmopolitan distribution of phlD-containing dicotyledonous crop-associated biocontrol pseudomonads of worldwide origin. FEMS (Fed. Eur. Microbiol. Soc.) Microbiol. Ecol. 37:105-116.

Zuber, S., Carruthers, F., Keel, C., Mattart, A., Blumer, C., Pessi, G. Gigot-Bonnefoy, C., Schnider-Keel, U., Heeb, S., Reimmann, C., and Haas, D. 2003. GacS sensor domains pertinent to the regulation of exoproduct formation and to the biocontrol potential of Pseudomonas fluorescens CHA0. Mol. Plant-Microbe Interact. 16:634-644.

\section{AUTHOR-RECOMMENDED INTERNET RESOURCES}

The EMBnet EMBOSS database: www.ch.embnet.org/EMBOSS/index.html United States Department of Energy Pseudomonas fluorescens genome website: genome.jgi-psf.org/draft_microbes/psefl/psefl.home.html

The Pseudomonas Genome Project Pseudomonas aeruginosa database: www.pseudomonas.com 